\title{
A physical approach on flood risk vulnerability of buildings
}

\author{
B. Mazzorana ${ }^{1}$, S. Simoni ${ }^{2}$, C. Scherer ${ }^{3}$, B. Gems ${ }^{4}$, S. Fuchs ${ }^{5}$, and M. Keiler ${ }^{6}$ \\ ${ }^{1}$ Department of Hydraulic Engineering, Autonomous Province of Bolzano, Bolzano, Italy \\ ${ }^{2}$ Mountain-eering S.r.l., Bolzano, Italy \\ ${ }^{3}$ Obrist \& Partner Engineering, Caldaro, Italy \\ ${ }^{4}$ Institute for Infrastructure Engineering, University of Innsbruck, Innsbruck, Austria \\ ${ }^{5}$ Institute of Mountain Risk Engineering, University of Natural Resources and Life Sciences, Vienna, Austria \\ ${ }^{6}$ Institute of Geography, University of Bern, Bern, Switzerland
}

Correspondence to: B. Mazzorana (bruno.mazzorana@provinz.bz.it)

Received: 18 December 2013 - Published in Hydrol. Earth Syst. Sci. Discuss.: 3 February 2014

Revised: 29 July 2014 - Accepted: 7 August 2014 - Published: 30 September 2014

\begin{abstract}
The design of efficient hydrological risk mitigation strategies and their subsequent implementation relies on a careful vulnerability analysis of the elements exposed. Recently, extensive research efforts were undertaken to develop and refine empirical relationships linking the structural vulnerability of buildings to the impact forces of the hazard processes. These empirical vulnerability functions allow estimating the expected direct losses as a result of the hazard scenario based on spatially explicit representation of the process patterns and the elements at risk classified into defined typological categories. However, due to the underlying empiricism of such vulnerability functions, the physics of the damage-generating mechanisms for a well-defined element at risk with its peculiar geometry and structural characteristics remain unveiled, and, as such, the applicability of the empirical approach for planning hazard-proof residential buildings is limited. Therefore, we propose a conceptual assessment scheme to close this gap. This assessment scheme encompasses distinct analytical steps: modelling (a) the process intensity, (b) the impact on the element at risk exposed and (c) the physical response of the building envelope. Furthermore, these results provide the input data for the subsequent damage evaluation and economic damage valuation. This dynamic assessment supports all relevant planning activities with respect to a minimisation of losses, and can be implemented in the operational risk assessment procedure.
\end{abstract}

\section{Introduction}

In European mountain regions, losses due to mountain hazards are still considerable high even if there is an ongoing debate on the overall increasing or decreasing trend (Fuchs, 2009; Gall et al., 2009). The concept of risk had been introduced in order to manage the resulting challenges, with respect to temporal and spatial dynamics of social (de Vries, 2007, Cutter and Finch, 2008) and engineering dimensions (Kienholz et al., 2004; Fuchs et al., 2013). Despite a relatively long tradition of the application of the risk concept in the European Alps (Kienholz et al., 2004), there still is a particular gap in the assessment of vulnerability (Fuchs et al., 2012a).

Scholars with various scientific backgrounds have a different understanding on the definition of vulnerability (Fuchs, 2009; Hufschmidt, 2011). Social scientists often focus on the characteristics of people or communities in terms of their capacity to anticipate, cope with, resist, and recover from the impact of a hazard (Wisner, 2004). In contrast, engineers and natural scientists define vulnerability as the degree of loss to an element at risk as a result of the impact of a hazard with a given frequency and magnitude (Fell et al., 2008), regularly assessed based on empirical data or modelled scenarios. As a consequence, there is neither a common definition for vulnerability nor a standardized methodology for an integrative vulnerability assessment available (Fuchs et al., 2007; Papathoma-Köhle et al., 2011), the only available concepts remain fragmentary with respect to a practical implementation (Birkmann et al., 2013). However, the different 
dimensions of vulnerability such as physical (structural), social, economic, or institutional vulnerability, although maybe differently defined, are connected to each other. Structural or physical vulnerability is hereby seen as a prerequisite or starting point, resulting in physical loss and may influence the other dimensions of vulnerability (Fuchs, 2009; Papathoma-Köhle et al., 2011; Kappes et al., 2012a, b).

Recently, the physical vulnerability of buildings exposed to torrent processes has been studied comprehensively in different mountain regions of Europe facing both the aim to compute vulnerability functions for use in operational risk assessment (Fuchs et al., 2007; Papathoma-Köhle et al., 2012; Totschnig and Fuchs, 2013) and to implement local structural mitigation measures (Holub and Fuchs, 2008; Holub et al., 2012, Hawkesbury-Nepean Floodplain Management Steering Committee, 2006). Despite these efforts, considerable research gaps still remain open: while the first studies combined empirical loss data with information on one process parameter (deposition height) resulting in damageloss functions, the latter studies were solely focused from a practical perspective on the reduction of structural vulnerability of individual buildings. Quan Luna et al. (2011) added a further step: Based on intensity information derived by numerical modelling back-analyzing the Selvetta debris-flow event, they presented vulnerability curves for the following independent variables: flow height $[\mathrm{m}]$, kinematic viscosity $\left[\mathrm{m}^{2} \mathrm{~s}^{-1}\right]$ and impact pressure $[\mathrm{kPa}]$.

The empirical vulnerability functions allow for an estimation of expected direct losses as a result of considered hazard scenarios which are based on a spatially explicit representation of process patterns and elements at risk categorized into defined typological classes. However, due to the underlying empiricism of such vulnerability functions, the transferability to other building types is limited (Papathoma-Köhle et al., 2011). The physics of the damage-generating mechanisms remains unveiled and restricts the applicability of the empirical approach for planning hazard-adapted buildings. In fact, as outlined by Fuchs (2009) and confirmed by Totschnig and Fuchs (2013), the analysis of empirical data from torrent processes has shown that the vulnerability of buildings affected by medium hazard intensities (e.g. $1.00-1.50 \mathrm{~m}$ deposition height for torrent processes) critically depends on the patterns of material intrusion through openings such as doors, wells and windows. This points out that in addition to the intensity of the physical impact and the structural response of the considered element at risk also the geometry characterizing the individual building has to be carefully considered in vulnerability analyses (Totschnig et al., 2011; Jakob et al., 2012; Jakob, 2013).

Moreover, previous studies have shown that spatial patterns in vulnerability of buildings exposed to torrent processes exist (Fuchs et al., 2012b) which cannot be satisfactorily explained only by the spatial and temporal process dynamics on the torrential fans. Therefore, a deeper insight into the mechanisms causing losses is necessary as a basis of any subsequent engineering design of feasible and economically efficient risk mitigation strategies (Mazzorana et al., 2012a, b; Mazzorana and Fuchs, 2010). Since in Alpine regions - due to an increasing scarceness of funding available public investments for natural hazard risk mitigation may decrease significantly, envisaged solutions must be convincing, both from a technical and economic viewpoint (Fuchs, 2013), and also be sustainable from an ecological perspective. This holds also for mainly private capital investments in terms of local structural protection strategies aiming at reducing the physical vulnerability of endangered buildings (Holub and Fuchs, 2009; Holub et al., 2012; Mazzorana et al., 2012b).

From a purely theoretical perspective rigorous approaches to vulnerability computations for structures can be derived from physical and numerical analyses of the fluid-structuresoil interaction with free surface flows. With respect to fluidstructure coupling, Walhorn et al. (2005) presented a monolithic model for fluid-structure interaction problems involving free surface using a space-time finite element discretization. They implemented a strong coupling algorithm and a time adaptable space-time finite element formulation to enforce conservation of momentum and mechanical energy at the fluid-structure interface. Moreover, they obtained an enhanced tracking of the fluid-solid interface through a refined level set method. However, reliable results have been provided so far only for simple geometrical configurations (e.g. single flexure elements impacted by a fluid flow) and the geomechanical processes have been neglected. Similar arguments hold for challenges involving the coupling between fluid flow and soil mechanics. Although front-end solutions for particular case studies have been obtained, so far there is a particular gap for the specific domain of mountain hazard risk management.

Therefore, we propose to treat the complex fluidstructure-soil interaction by decoupling it considering the following distinct analytical steps:

a. For a comprehensive physically based concept of vulnerability evaluation, a very detailed representation of the impacting hazard process is necessary with respect to both space and time.

b. To quantify the resulting impacts on the building envelope and to detect possible liquid and solid material intrusion pathways, the geometrical structure of buildings has to be analysed with respect to the time-varying flow field of the impacting process and, if geomechanical actions may interfere, with respect to the residual bearing capacity of the soil layers the construction is situated.

c. Once quantified the time-varying impact spectrum, the physical response (i.e. resistance) of the building structure has to be evaluated, mainly from a structural analysis perspective (statics, elastostatics and dynamics) and from a building physics viewpoint. The analytical step (c) should result in a comparison of the stresses 
and strains on structural elements focusing on admissible values providing the short term effects for their structural integrity.

Moreover, the physical processes taking place on and through the building envelope which may exhibit longlasting consequences (e.g. material intrusion and moisture transfer and accumulation, wetting and drying of the outer and inner layers of the building) should be described. The basic product of this analytic step is the damage susceptibility profile containing the results of a set of ultimate limit state, serviceability limit state, durability limit state and no material intrusion verifications. Furthermore, these results provide the input data for the subsequent damage evaluation and economic damage valuation.

Subsequently, based upon the derived response (in terms of a damage susceptibility profile of the considered building structure), scenarios reflecting the post-impact status of the considered residential building, along with the consequences in terms of damage for the electrical heating and hydraulic system as well as other values, have to be considered. For potential damage analysis Mazzorana and Fuchs (2010) developed a structured procedure to elicit and integrate expert knowledge. Papathoma-Köhle et al. (2012) provides an approach for economic damage estimation and Gallerani et al. (2011) discuss the most probable reinstatement value to restore the full functionalities of the original building. In Fig. 1 the steps of a physically based assessment procedure are shown in a workflow.

Following the workflow presented in Fig. 1 our contribution in this paper is directed at unveiling the sequences of significant loss generation mechanisms, both methodologically and computationally. We will derive simplified computational schemes to perform structural analyses for specific impact spectrums (e.g. negligible geomechanical actions) and check whether potential material intrusion into the element at risk might take place. Finally we will discuss the added value of the presented methodological approach for the planning of both functionally and economically efficient local structural measures as a complement to conventional mitigation strategies. By evaluating the potential damages, the scope of application of vulnerability assessments is expanded beyond its classical role as a decision-support tool and is closely linked to the core of the planning process.

\section{Method}

\subsection{Overview}

In this section we address in detail the first three steps of the necessary five analytic steps to accurately assess the physical vulnerability of the built environment:

a. Process modelling, which leads to a spatially explicit and time-varying quantification of the process related primitive variables expressing its intensities; b. Impact modelling, which leads to the time-varying representation of the actions and effects the building structure is subjected to structural and physical response modelling;

c. Structural and physical response modelling, which consists in a verification of a well-defined set of limit states (i.e. ultimate, serviceability limit states) as well as the verification of non-intrusion conditions for the liquid and solid process volumes.

The remaining two steps, damage modelling and the economic loss valuation, have been extensively covered e.g. in Mazzorana et al. (2012b, c, 2013).

A prerequisite for the above listed methodological steps is to define for each considered element at risk a suitable control volume and convenient control sections where the process intensities and magnitudes have to be traduced into defined loading configurations (i.e. actions). Hence, we define a control volume of minimum extent of parallelepiped form entirely containing the considered element at risk (compare Fig. 2).

To account for geomechanics, it is necessary to define additional control sections extending beyond the previously defined control volume. This is done by encompassing the building and the entire elevation profile and extending it to the stream cross sections subjected to relevant incision processes (compare Fig. 2). Taking a local coordinate system $x^{\prime}$, $y^{\prime}, z^{\prime}$ for the considered element at risk, $p=1, \ldots, P$ control sections $A_{\mathrm{p}}$ are identified by the vertical planes of the parallelepiped control volume. The control sections containing the elevation profiles for geomechanical analysis are variably oriented vertical planes symbolized by $A_{r, z^{\prime}}$ (where the intersection between $r$ and the base area of the building is a nonempty set).

\subsection{Process modelling}

\subsubsection{Fluid flow process}

Relevant fluid flow processes in this context are floods, fluvial sediment transport, debris floods and debris flows (Pierson and Costa, 1987; Slaymaker, 1988). Moreover, large wood (LW) is increasingly recognized as one of the main problems for risk assessment in Alpine streams (Mazzorana et al., 2011), mostly because of the LW potential to (1) trigger more severe flood inundations due to dam-break surges downstream of temporary wood dams (Mao and Comiti, 2010), (2) clog bridges and narrow sections (Diehl, 1997; Comiti et al., 2008), and (3) increase the destructive power of debris flows (Ishikawa, 1990).

As outlined by Armanini et al. (2009) debris flows can be interpreted as rapid massive sediment motions that occur in relatively small and steep catchments. Large amounts of sediment can become unstable in particular geomorphological situations and under extreme meteorological conditions 


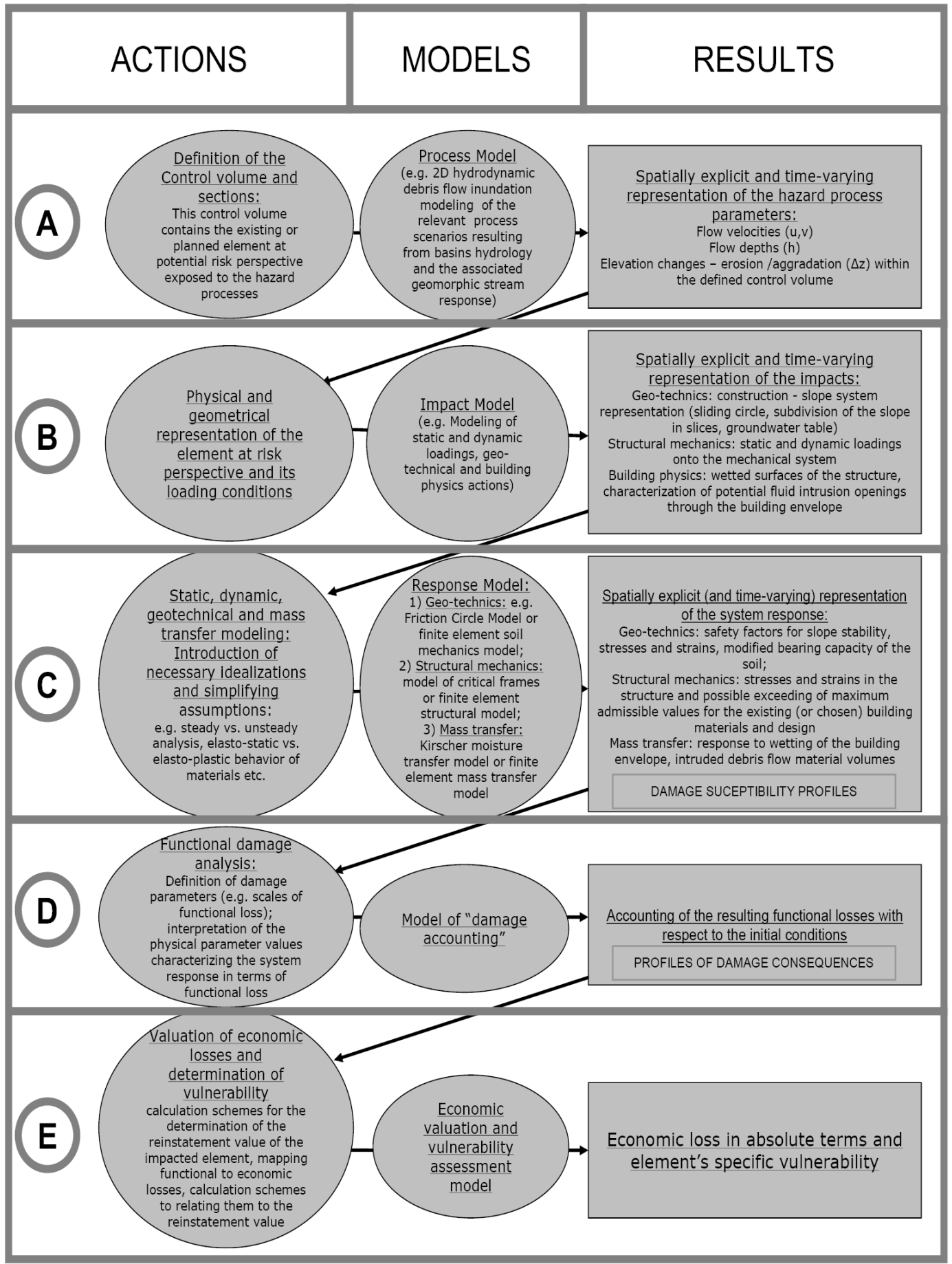

Figure 1. Overview of the physically based vulnerability assessment procedure, analytic steps A through E. Please note steps D and E are not explicitly addressed in this paper, for details refer to Mazzorana et al. (2012c).

(intense rainfalls) and flow by gravity as a dense mixture of water and sediments (Iverson, 1997).

Mathematically, debris flows can be described as a twophase fluid composed by an interstitial liquid (water) and by granular matter (sediments) that constitutes the solid phase and has proper rheological properties (Pitman and Le, 2005; Rosatti et al., 2013). In the particular, accurate computational modelling approaches have been recently proposed either in a 1-D or in a 2-D setting (e.g. Rosatti and Fraccarollo, 2006; Rosatti et al., 2013), considering the very relevant case of 


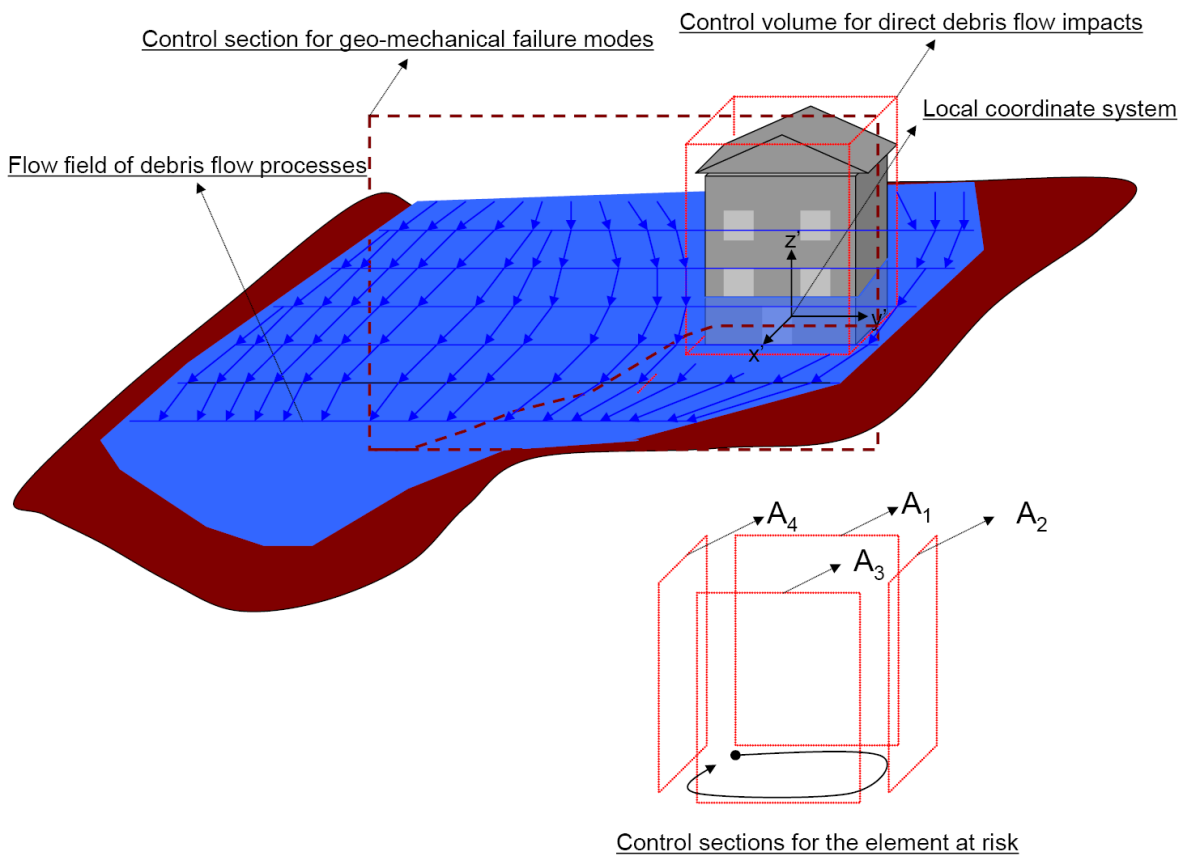

Figure 2. System of control volume and control sections adopted for representing the loading configuration for the considered element at risk. The lateral plains of the control volume identify the control sections through which the debris-flow mass may enter or leave the control volume.

flows of water-sediments mixture without cohesive properties and, hence, with negligible fractions of clay and silt. Whereas plastic stresses may play a significant role due to significant fractions of clay and silt additional research efforts are still needed to computationally implement the most advanced rheological findings.

2-D modelling approaches are required for process representation accurate in space and time for allowing a technically sound and physically based vulnerability assessment of endangered buildings. Prior to this analytic step, a detailed process routing along the stream network where the sediment volumes are mobilized and along which the water and sediment fluxes are transferred is necessary (Hübl et al., 2003). With respect to the preliminary process routing step, a comprehensive methodology has recently been proposed by Mazzorana et al. (2012a). Endowed with reliable process scenarios in terms of both liquid and solid discharges at critical nodes (e.g. apexes of alluvial fans), the subsequent step consists in representing the process propagation in space and time in those areas where the assets at risk are located. Regarding the debris-flow simulation process in the endangered area, the two-dimensional simulation model over mobile bed - TRENT 2-D - developed by Armanini et al. (2009) and substantially enhanced by Rosatti et al. (2013) has been applied. In this model the system of partial differential equations derived from the mass and momentum conservation principles is hyperbolic and characterized by a non-conservative nature. The details about the mathematical model and the associated finite-volume, explicit Godunov-type numerical approach are documented in Rosatti et al. (2013). Applying this approach for each cell of the computational domain and for each time step values for the transposed vector of primitive physical variables, $\boldsymbol{W}$, can be extracted by the following:

As previously stated $\boldsymbol{W}=\left(h_{\mathrm{DF}}, u, v, z_{\mathrm{b}}\right)^{T}$ is the transposed vector of primitive physical variables, where $h_{\mathrm{DF}}$ is the flow depth, $u, v$ are the depth-averaged velocities in $x$ and $y$ direction respectively, and $z_{\mathrm{b}}=h_{\mathrm{D}}+h_{\mathrm{S}}$ is the elevation of the mobile bed, which consists of the thickness of the pre-existing soil layer $h_{\mathrm{S}}$ above a datum and the thickness of the deposit $h_{\mathrm{D}}$. Rigorously, the thickness of the pre-existing soil layer can diminish if erosion of the soil stratum takes place.

Since the subsequent analytic step is the quantification of the impacts on the endangered building under consideration, first the values of the primitive variables for the computational cells have to be calculated for each cell along the above-defined control sections for each time step within the event duration, namely $\boldsymbol{W}_{A_{\mathrm{p}}}\left(t_{k}\right)$, with $k=1, \ldots, K$, where $K$ is the total number of considered time steps. Second, the evolution of the bed elevation profiles $\boldsymbol{Z}=\left(z_{\mathrm{b}, 1}, \ldots, z_{\mathrm{b}, \mathrm{R}}\right)^{T}$ in the vertical planes $A_{r, z^{\prime}}$, which identify the cross sections for geotechnical analysis (where the subscript $r=1, \ldots, R$ identifies the computational cells along $\boldsymbol{r}$ ), have to be computed. 

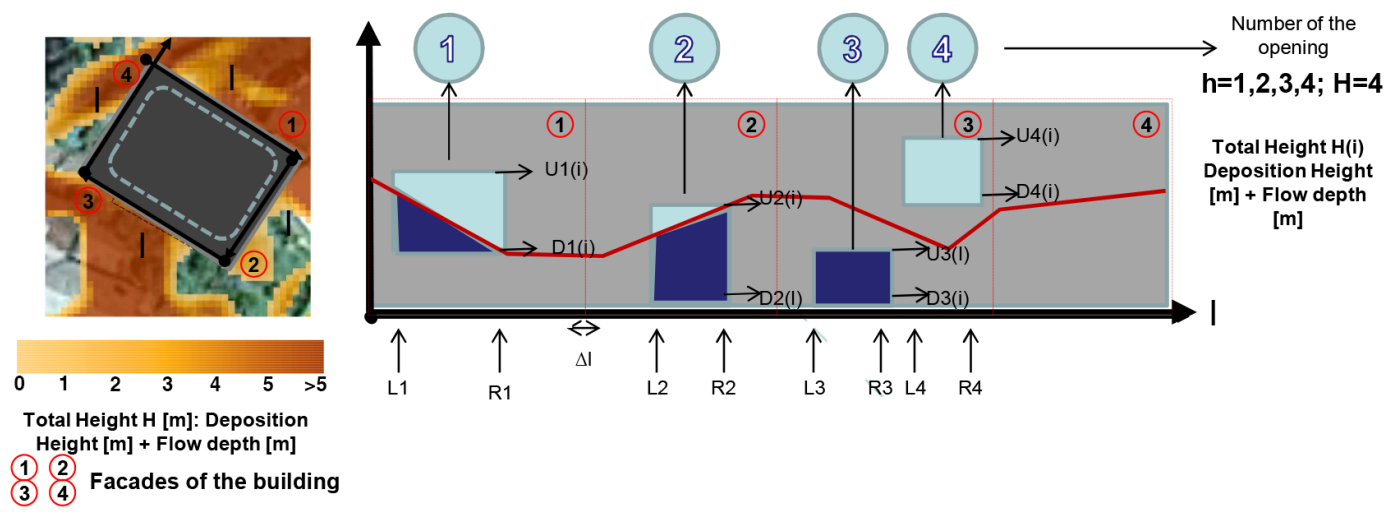

Figure 3. Definition sketch for the determination of potential material intrusion and building physics consequences.

\subsubsection{Geomechanical process}

The 2-D soil-structure models for each $A_{r, z^{\prime}}$ might be represented differently depending on the chosen geomechanical analysis approach. In more simple cases of slope stability computations the slip circle method with its slice-based discretization is commonly used, whereas in more complex cases modern stability computation techniques are based on a finite element analysis with peculiar finite element discretization approaches (Plaxis, 2011).

\subsection{Impact modelling}

\subsubsection{Preliminary considerations}

According to Fig. 1 and following the digressions of the previous subsection we characterize the impact from a fluid dynamics perspective, from a building physics point of view and from a geomechanical perspective. Concerning the impacts deriving from fluid dynamic actions we first set the analytic focus on determining the loads on the envelope of the building and in a second stage, if material intrusion is relevant, additional loading configurations have to be considered.

As a preliminary step the structural and geometrical idealizations have to be defined:

a. For the purposes of structural analysis the considered building can be idealized in a variety of ways depending on the necessary level of sophistication required to represent its structural and physical characteristics. As a general procedure, suitable for different degrees of complexity, we suggest the application of matrix methods and finite element methods, each one endowed with particular discretization approaches (e.g. Steinke, 2012).

b. For the purposes of material intrusion analysis and for building physics considerations we ideally approach the envelope of the building in clockwise sense along a coordinate $l$, with $0 \leq l \leq L$, traced along the perimeter of the base area of the building, as shown in Fig. 3.
The openings are enumerated progressively with $h$, $h=1, \ldots, H$ and their geometry is tracked with the functions, $U(l)$ and $D(l)$, identifying their upper and lower cord between $L_{h}$ and $R_{h}$ along the coordinate $l$, respectively. The maximum elevation of the envelope of the building along $l$ is given by $E(l)$.

\subsubsection{Fluid flow impacts relevant for structural and physical response analysis}

The main aim is the representation of the direct static and dynamic loadings (actions) exerted by the debris-flow impact on the building's envelope in terms of pressure distributions (pressures in $\left[\mathrm{N} \mathrm{m}^{-2}\right]$ ). Considering a vertical wall impacted by a debris flow it has to be determined whether the debrisflow surge approaches the element at risk as confined or unconfined flow, and distinct impact mechanisms have to be considered.

In case of an unconfined flow behaviour which can be considered as an external flow with respect to the element at risk, the assumed dynamic pressure exerted on the wall is (Holub et al., 2012):

$q_{\mathrm{p}}=\frac{1}{2} \cdot C_{\mathrm{f}} \cdot \rho_{\mathrm{df}} \cdot v^{2}$,

where $C_{\mathrm{f}}$ is the drag coefficient which depends on the shape of the obstacle and the flow characteristics of the debris-flow mixture, $\rho_{\mathrm{df}}$ is the density of the debris-flow mixture and $v$ is the depth-averaged velocity component orthogonal to the projected area of the obstacle on a plane normal to the flow direction. In case of almost confined flow situations which typically occur if incised flow paths develop on the debris cone and the element at risk is located along such a flow path, Holub et al. (2012) suggest the following expression to account for the dynamic pressure:

$q_{\mathrm{p}}=\rho_{\mathrm{df}} \cdot v^{2}$.

Regarding the special case of totally confined debris-flow impacts on a vertical wall, we refer to the debris-flow impact 


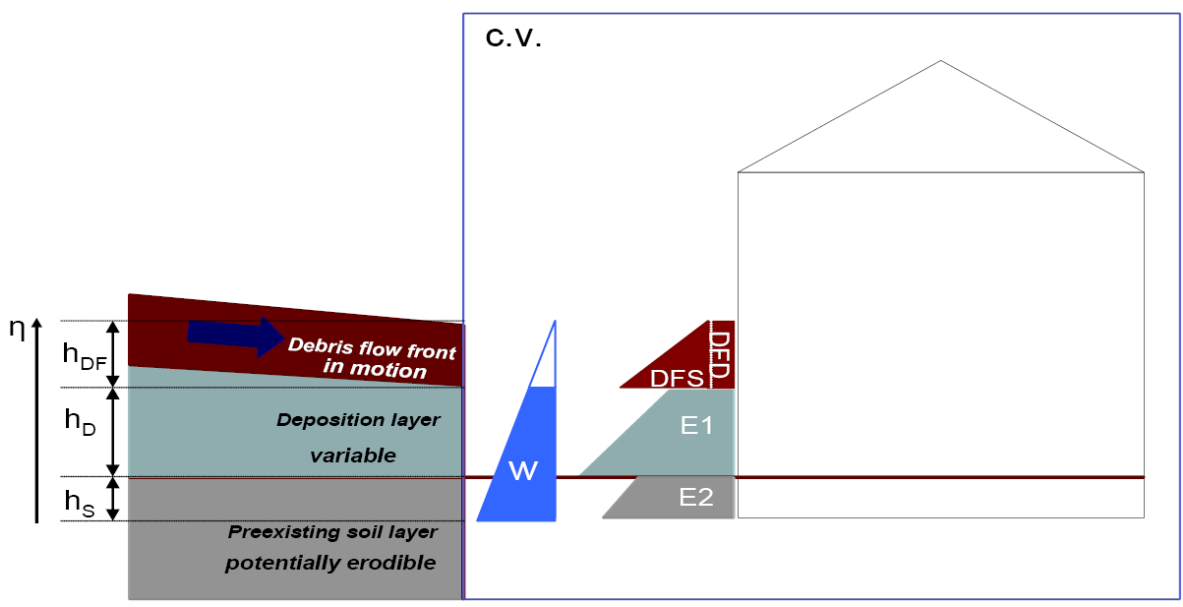

Figure 4. Qualitative scheme of the debris-flow process configuration and the resulting pressure distribution on the exposed portion of the building.

theory of Armanini et al. (2011). Whereas the latter impact case is typical for check dams impacted by almost canalized debris flows, it is rather the exception on alluvial fans where debris flows propagate and deposit. Hence, acknowledging that further experimental evidence is needed to refine the debris-flow impact assessments for the former flow cases, we adopt Eqs. (1) or (2) to assess the dynamic debris-flow impact pressure.

We assume that the pressure distribution on the building envelope is caused by the impact of a debris-flow front, accounting for both dynamic and static components, symbolized with DFS and DFD respectively, passing over saturated strata of debris-flow deposits (e.g. aggradations formed during the event duration preceding the main surge) and the soil layer and which exert both earth and hydrostatic pressure on the building envelope (E1, E2 and W, compare Fig. 4).

Taking the process model results as a basis, we can deduce for each control section $A_{\mathrm{p}}$ the structure of the pressure distribution for each computational time step $t_{k}$ as follows: indicating with $h_{\mathrm{DF}}, h_{\mathrm{D}}, h_{\mathrm{S}}$ the flow depth of the front, the overall thickness of the deposits and of the soil stratum above the building basement level, and adopting the notations $p_{\mathrm{DFT}}, p_{\mathrm{DFD}}, p_{\mathrm{DFS}}, p_{\mathrm{S}^{\prime}, \mathrm{D}^{\prime}}, p_{\mathrm{S}, \mathrm{S}}$, and $p_{\mathrm{W}}$ to identify the total debris-flow pressure, the constant value of the dynamic debris-flow pressure, the static debris-flow pressure, the deposit earth pressure at $\eta=h_{\mathrm{S}}+h_{\mathrm{D}}$ (in consideration of the weight of the overflowing surge), the soil earth pressure at $\eta=0$ and the hydrostatic pressure at $\eta=0$ (building basement level), the pressure distribution $p(\eta)$ can be formalized as follows:

$p(\eta)=\left\{\begin{array}{c}p_{\mathrm{SS}}-\frac{p_{\mathrm{SS}}-p_{\mathrm{S}^{\prime}}{ }^{\prime}}{h_{\mathrm{S}}+h_{\mathrm{D}}} \cdot \eta+p_{\mathrm{W}}-\frac{p_{\mathrm{W}}}{h_{\mathrm{S}}+h_{\mathrm{D}}+h_{\mathrm{DF}}} \cdot \eta \\ \quad \text { for } 0 \leq \eta<h_{\mathrm{S}}+h_{\mathrm{D}} \\ p_{\mathrm{DFT}}-\frac{p_{\mathrm{DFS}}}{h_{\mathrm{DF}}} \cdot \eta+\frac{p_{\mathrm{DFS}}}{h_{\mathrm{DF}}} \cdot\left(h_{\mathrm{S}}+h_{\mathrm{D}}\right) \\ \quad \text { for } h_{\mathrm{S}}+h_{\mathrm{D}} \leq \eta<h_{\mathrm{S}}+h_{\mathrm{D}}+h_{\mathrm{DF}}\end{array}\right.$ with

$$
\begin{aligned}
p_{\mathrm{DFD}} & =\frac{1}{2} \cdot C_{\mathrm{f}} \cdot \rho_{\mathrm{df}} \cdot v^{2}, \\
p_{\mathrm{DFS}} & =\rho_{\mathrm{df}} \cdot g \cdot h_{\mathrm{DF}}, \\
p_{\mathrm{DFT}} & =\rho_{\mathrm{df}} \cdot g \cdot h_{\mathrm{DF}}+\frac{1}{2} \cdot C_{\mathrm{f}} \cdot \rho_{\mathrm{df}} \cdot v^{2}, \\
p_{\mathrm{S}^{\prime}} & =\gamma_{\mathrm{DF}} \cdot h_{\mathrm{DF}} \cdot K_{\mathrm{a}} h_{\mathrm{D}}, \\
p_{\mathrm{SS}} & =p_{\mathrm{S}^{\prime} \mathrm{D}^{\prime}}+\left(\gamma_{\mathrm{S}}-\gamma_{\mathrm{W}}\right) \cdot\left(h_{\mathrm{D}}+h_{\mathrm{S}}\right) \cdot K_{\mathrm{a} h_{\mathrm{D}}},
\end{aligned}
$$

and

$p_{\mathrm{W}}=\gamma_{\mathrm{W}} \cdot\left(h_{\mathrm{D}}+h_{\mathrm{S}}+h_{\mathrm{DF}}\right)$.

In Eq. (3), $K_{\mathrm{a} h_{\mathrm{D}}}$ is the active earth pressure coefficients of the deposition stratum (including the pre-existing soil layer), $g$ is the acceleration of gravity, $\rho_{\mathrm{df}}$ and $\gamma_{\mathrm{df}}$ are the density and the specific weight of the debris flow, $v$ is the local velocity of the debris flow evaluated in normal and inwardly oriented direction with respect to the perimeter of the considered building.

For the computation of the area of the openings subjected to material intrusion we evaluate for each computational time point $t_{k}$ with reference to the definition sketch shown in Fig. 3:

$\operatorname{Diff}\left(l, t_{k}\right)=H\left(l, t_{k}\right)-D_{\mathrm{h}}(l)$ if $D_{h}(l)<H\left(l, t_{k}\right) \leq U_{h}(l)$

$\operatorname{Diff}\left(l, t_{k}\right)=U(l)-D_{h}(l)$ if $H\left(l, t_{k}\right)>U_{h}(l)$ and

$\operatorname{Diff}\left(l, t_{k}\right)=0$ if $H\left(l, t_{k}\right) \leq D_{h}(l)$, where

$H\left(l, t_{k}\right)=h_{\mathrm{DF}}\left(l, t_{k}\right)+z_{\mathrm{b}}\left(l, t_{k}\right)$.

The wetted area of the considered opening $h$ is therefore

$O_{h}\left(t_{k}\right)=\int_{L_{h}}^{R_{h}} \operatorname{Diff}\left(l, t_{k}\right) \mathrm{d} l$. 
The total area available for potential material intrusion is given by the sum of the wetted parts of all openings $h=1, \ldots, H$ :

$\mathrm{TO}_{\mathrm{H}}\left(t_{k}\right)=\sum_{h=1}^{\mathrm{H}} O_{h}\left(t_{k}\right)$.

To evaluate the area of wetted envelope of the building we proceed analogously, by computing first:

$\operatorname{DIFF}\left(l, t_{k}\right)=H\left(l, t_{k}\right)$ if $H\left(l, t_{k}\right) \leq E(l)$,

where $E(l)$ is the maximum elevation of the envelope at $l$ and

$\operatorname{DIFF}\left(l, t_{k}\right)=E(l)$ if $H\left(l, t_{k}\right)>E(l)$.

The wetted area of the building envelope is therefore:

$\mathrm{WE}\left(t_{k}\right)=\left[\int_{0}^{L} \operatorname{DIFF}\left(l, t_{k}\right) \mathrm{d} l\right]-\mathrm{TO}_{\mathrm{H}}\left(t_{k}\right)$.

\subsubsection{Geomechanical impacts relevant for structural response analysis}

Depending on the results of the analysis of the geomechanical processes (compare Sect. 2.2.2) the associated impacts relevant for structural response analysis are modelled by assuming a lowered bearing capacity of the soil supporting the building.

\subsection{Structural and physical response analysis}

The set of norms EN 1990 (Eurocode 0: Basis of Structural Design), EN 1991 (Eurocode 1: Actions on Structures) and the specific design codes EN 1992 to EN 1999 inspired our concept of structural response analysis and the physical response analysis concept is analogously set up.

In particular EN 1990 is based on the limit state concept used in conjunction with the partial safety factor method. In this context limit states are intended as states beyond which the structure no longer fulfils relevant design criteria. Two different types of limit states are considered, namely ultimate limit state and serviceability limit state (compare Gulvanessian, 2009). As stated in EN 1990 it has to be verified, based on the application of load models and structural models, that no limit state is exceeded when the design values for actions, material properties and geometrical data are used. Here (a) the ultimate limit states (ULS) and (b) the serviceability limit states (SLS) are briefly illustrated in their essential aspects.

a. Ultimate limit states - ULS: the exceeding of these limit states may result in a structural collapse or other forms of structural failures. They are related to the safety of people and/or the safety of the structure. In this context EN 1990 prescribes the following set of verifications:
- ECU: loss of static equilibrium of the entire structure or of specific parts, all considered as rigid bodies. In this case small deviation of the value and the spatial distribution of the considered action type (e.g. dead weight of the structural parts) are relevant, whereas the strength of construction materials or the building ground are of no influence;

- STR: failure or excessive deformation of the structure or its parts including the foundation, piles. Here the bearing capacity and the strength of materials are relevant;

- GEO: failure or excessive deformation of the building ground, whereas the bearing capacity of the soil (or rock) is decisive;

- FAT: failure of the structure as a consequence of fatigue.

All the above-reported verifications consist in a comparison between the design values for the effects of the actions on the building of interest and the design values for the corresponding resistances, namely

$\mathrm{ECU}: E_{\mathrm{d}, \mathrm{dst}} \leq R_{\mathrm{d}, \mathrm{stb}}$,

where $E_{\mathrm{d}, \mathrm{dst}}$ is the design value of the effects of the destabilizing actions, $R_{\mathrm{d}, \mathrm{stb}}$ is the design value of the effects of the stabilizing actions,

STR or GEO : $E_{\mathrm{d}} \leq R_{\mathrm{d}}$,

where $E_{\mathrm{d}}$ is the design value of the effects of actions and $R_{\mathrm{d}}$ is the design value of the corresponding resistances.

This verification approach is based on the partial factor method which incorporates a semi-probabilistic safety concept (compare Feix and Walkner, 2012 for details); a representation is provided in Fig. 5.

The ultimate limit states have to be verified for particular design situations representing the sets of physical conditions reflecting the real conditions occurring during the construction and use of the structure. The reference design situation for natural hazard impact is that of an accidental situation.

b. Serviceability limit states - SLS: these limit states correspond to a situation if defined conditions are no longer met and specified service requirements for a structure or a structural element are needed (compare Gulvanessian et al., 2004). The design situations to be considered in this case are structural function of the entire building or of a portion, the comfort of people and the appearance of the building. To assess these limit states the following criteria can be adopted: limitation of strain, deformations, crack widths and oscillations. These types of assessments consist in a comparison between the design 

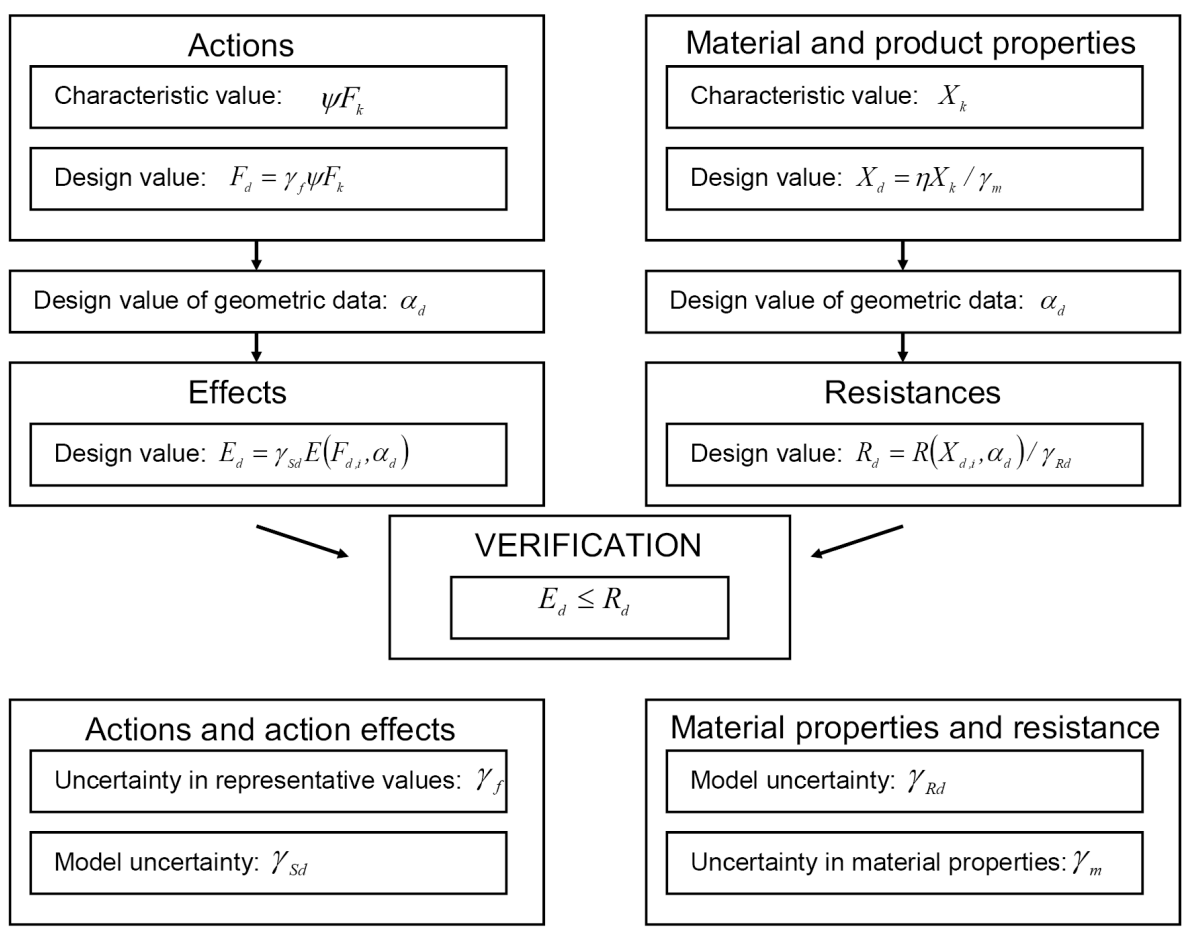

Figure 5. Verification scheme by the partial factor method (after Gulvanessian et al., 2004).

values of the effect $-E_{\mathrm{d}}$ - and of the upper limit of the considered serviceability design criteria $-C_{\mathrm{d}}$ :

$E_{\mathrm{d}} \leq C_{\mathrm{d}}$

For complex structural settings it is convenient to use the finite element method - FEM. For specific details about modelling aspects and algorithms employed, the reader is referred to the well-established literature (compare for example Zienkiewicz et al., 2005).

c. No material intrusion limit state - NLS: analogue to the design basics outlined above and in agreement with the methodological approaches outlined in the previous subsections, we add a supplementary limit state, the no intrusion (permeability) limit state. This state is defined as the requirement of that the openings should not be exposed to wetting throughout the event duration and is formalized as follows:

$$
\mathrm{TO}_{\mathrm{H}}\left(t_{k}\right)=\sum_{h=1}^{\mathrm{H}} O_{h}\left(t_{k}\right)=0 \quad \forall t_{k} .
$$

The limit states formalized above (compare Eqs. 7 to 10) can be used to define a damage susceptibility profile for the considered building.

The damage susceptibility profile contains the verification for the relevant design situations and for all time steps $t_{k}$ of the ULS, the SLS and the NLS. Since the relevance of both ULS and NLS is indisputable for the generation of direct damages, these limit states are considered in our analytic setup.

Once the damage susceptibility profile is comprehensively elaborated for the building of interest, including also the ad hoc defined no material intrusion and no wetting damage verification (Eq. 10), it is necessary to infer the possible profile of damage consequences, whose elaboration is essentially based on expert opinions elicited and structured through appropriated scenario development techniques (compare Mazzorana et al., 2012a). The proposed analytic setup allows for a comprehensive description of the damage response behaviour of the building envelope. Since the flow process through the building is not simulated, an expert based derivation of stochastic event trees might be helpful in hypothesizing the full range of possible damage consequences of the considered building. In this case, however, subjective probability assignments are necessary. For a comprehensive treatment of rigorous elicitation methods for subjective probabilities we refer to Wakker (2010). Consequently, the economic damage can be calculated (Papathoma-Köhle et al., 2012).

The damage susceptibility profile represents the ideal starting point of the planning process aiming at providing optimal object protection, since the final aim of the planning efforts is to verify that the building under consideration is hazard-adapted. 


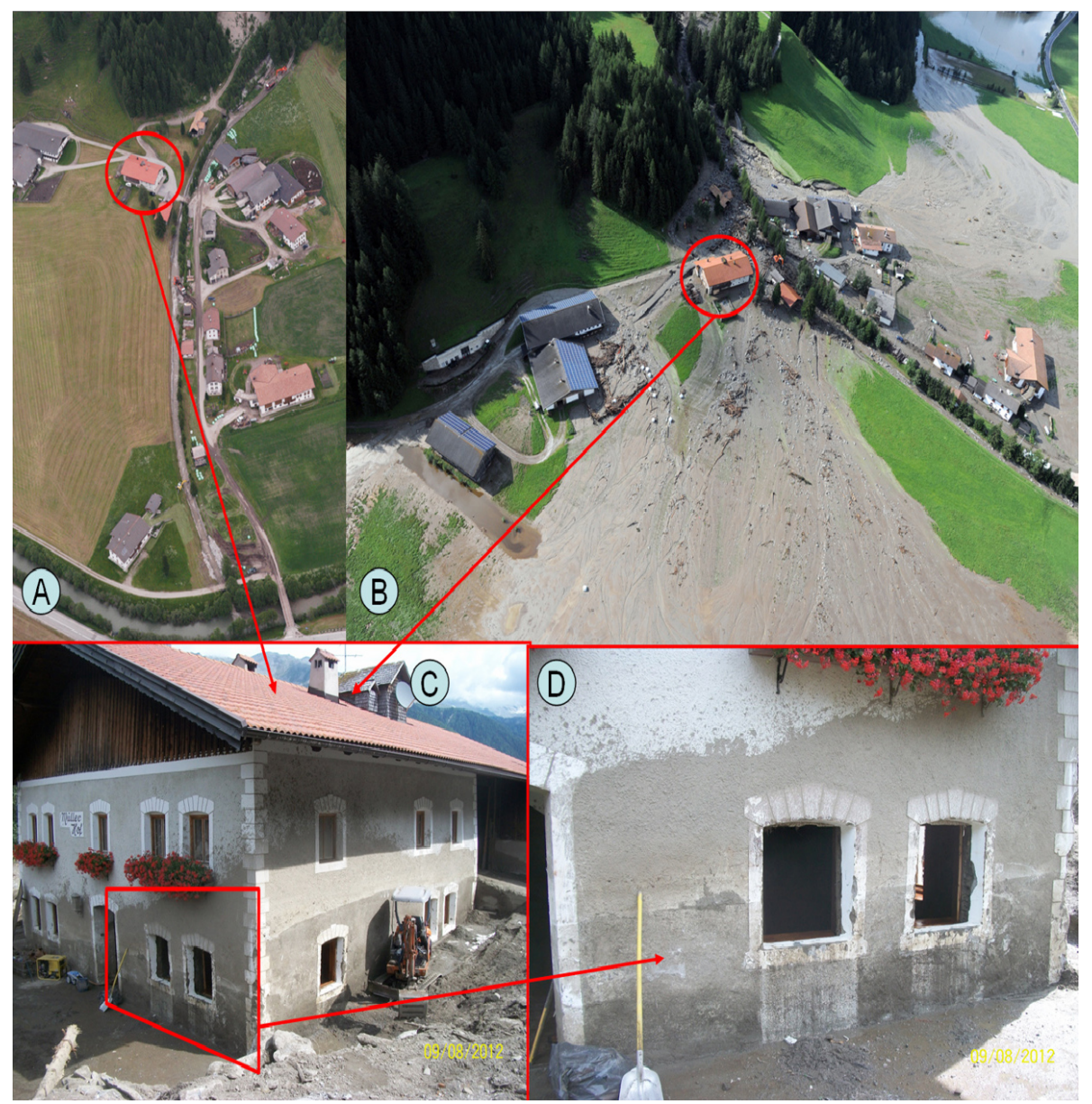

Figure 6. Location on the debris cone and details about the damage process for the selected residential building example. (a) Configuration of the settlement area and detailed location of the example building (pre-event situation); (b) depositional process patterns on the debris cone and location of the example building; (c) and (d) detailed views on the impact mechanisms and the damage processes for the considered building.

\section{Application to a case study}

In this section we present a practical application of the analytic steps outlined in Sect. 2, taking as an example a residential building, which is located on the debris cone of the Grossberg torrent, Italian Alps. In the 1970s a trapezoidal channel was built in the fan area to prevent damages on houses and crops. The channel cross section $\left(5.6 \mathrm{~m}^{2}\right)$ was designed for a liquid discharge $45 \mathrm{~m}^{3} \mathrm{~s}^{-1}$; additionally a large slit dam with an available retention volume of $19000 \mathrm{~m}^{3}$ was built in 2009 at the fan apex to protect the downstream village. On 4 August 2012, an event occurred with a debris volume of $53000 \mathrm{~m}^{3}$ and seriously damaged several residential buildings in the debris cone area (see Fig. 6). Following the analytic structure employed in Sect. 2 we first set up a validated process model for this debris-flow event, than we derive the relevant impacts on the buildings envelope and successively we proceed by modelling the structural and physical response.

\subsection{Process modelling}

With respect to the full procedure outlined in the previous sections it is admissible to restrict the investigation to the analysis of the fluid flow processes since geomechanical processes can be neglected for the specific case.

By means of two-dimensional debris-flow simulation model over mobile bed - TRENT 2-D - (Armanini et al., 2009; Rosatti et al., 2013) the event of 4 August 2012 was reconstructed by using the detailed event documentation data.

\subsubsection{Process analysis}

A convective storm hit the Pfitsch valley on 4 August 2012; cumulated rainfall in $6.25 \mathrm{~h}$ reached $45 \mathrm{~mm}$. Using the intensity-duration-frequency curve for the area provided by the Hydraulic Engineering Department of the Autonomous Province of Bolzano the storm can be classified approximately as a 300-year return-period event. The storm 


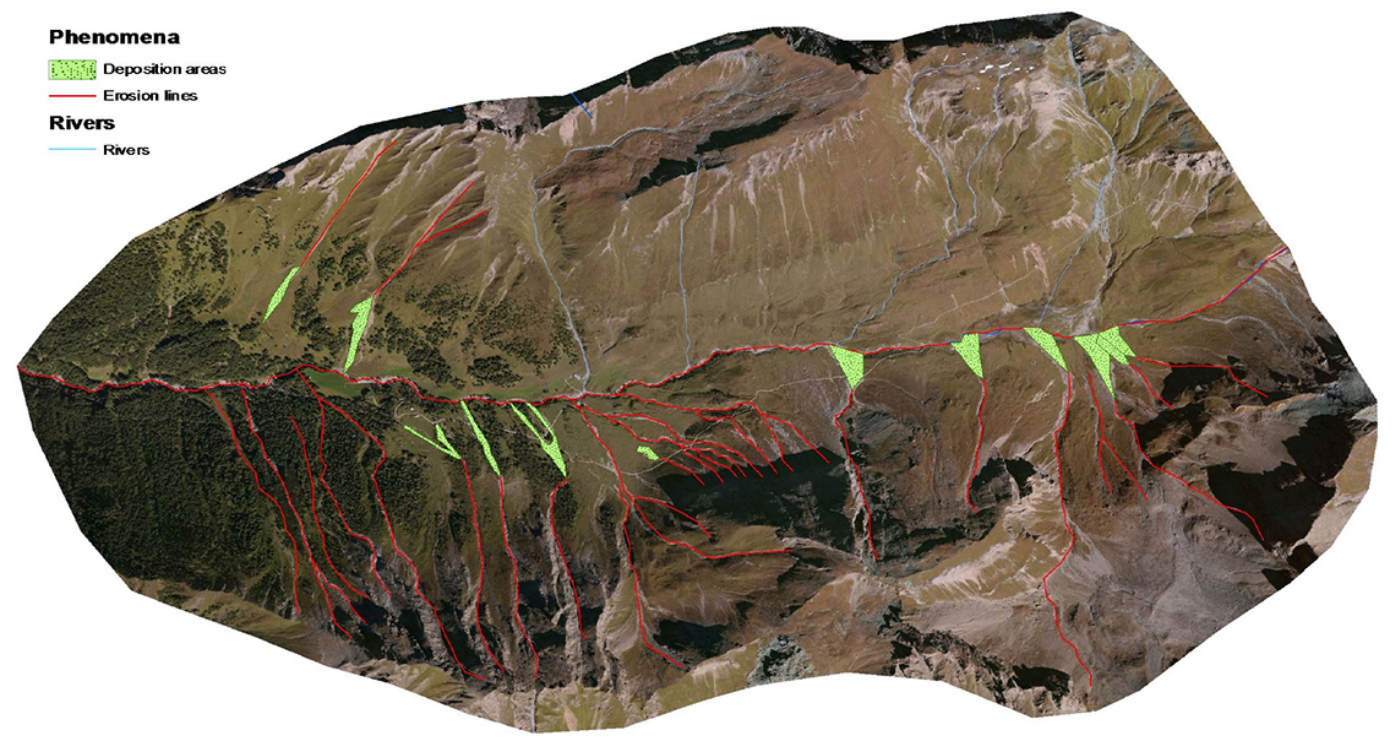

Figure 7. Overview of the triggering areas and the main erosion and deposition phenomena.

originated in the western part of the Province (Passer valley) and moved in north-west direction, towards the Upper Isarco valley where roughly 30 debris and mudflows were triggered. Triggering conditions have been exacerbated by abundant precipitations, occurred during the previous month, leading to a partial saturation of the soil (total cumulated rainfall in July was $230 \mathrm{~mm}$ in Vipiteno). Figure 7 shows triggering areas scattered over the steep landscape.

The watershed of the Gossbergbach is characterized by an area of $10 \mathrm{~km}^{2}$, ranging from 1420 to $3130 \mathrm{~m}$ a.s.l. The steepness of the valley side and the availability of sediments enhanced the process. Figure $8 \mathrm{a}$ and $\mathrm{b}$ display the steepness of the channel in the proximity of the slit dam and the tendency towards debris-flow initiation, according to Cavalli and Marchi (2006). Red dots indicate channel sections where the ratio between the contributing area and the local slope can cause soil failure.

Hydrological and hydrodynamics modelling was undertaken with the purpose of quantifying static and dynamic loadings exerted by the debris-flow impact on the target building and their evolution in time. In particular, flow velocities (for each control section), flow height and deposit thickness for this specific event are identified. The computational 2-D domain was chosen with the purpose of focusing on the spreading of the debris flow along the fan, i.e. downstream the slit dam. The rational for this was the knowledge of the total volume deposited on the fan. The volume was measured through intensive field campaigns carried out by the Hydraulic Engineering Department few days after the event.

Hydrological and hydrodynamics modelling was undertaken with the purpose of quantifying static and dynamic loading impact of the debris flow on the target building and their evolution in space and time. In particular, for this specific event, flow velocities, flow heights, and deposit thickness were computed and compared to measured values. Patterns of deposits were measured by intensive field surveys carried out by the Hydraulic Engineering Department of Bolzano few days after the event and used for model calibration. The computational 2-D domain was chosen with the purpose of focusing on the spreading of the debris flow along the fan, i.e. downstream the slit dam. An additional rational for this choice was that the patterns of deposition and the total volume deposited an the fan were known. The total volume was estimated to be $53000 \mathrm{~m}^{3}$ Boundary conditions were given in terms of liquid and solid hydrograph; the liquid hydrograph was derived using a back-analysis approach aiming at reproducing field observations, i.e. the event duration (roughly $6 \mathrm{~h}$, compare Fig. 9) and the total amount of transported sediment (i.e. flow transport capacity). The liquid boundary condition was computed using a geomorphic, semi-distributed hydrological model (Rigon et al., 2011) which accounts for different resident times characterizing various portions of the watershed. The rainfall input to the model was derived from measured rainfall data. Solid inflow boundary conditions were calculated on the gradient basis of the stream, the average characteristics of the transported sediments (internal friction angle, $d_{50}$ ), and the liquid hydrograph.

\subsubsection{Results of process analysis}

Results are displayed in Fig. 10c in terms of deposition thickness. Figure 10a and $b$ offer a comparison with the observed event. Considerations on the maximum local velocities may additionally help to validate the modelling results. As shown 

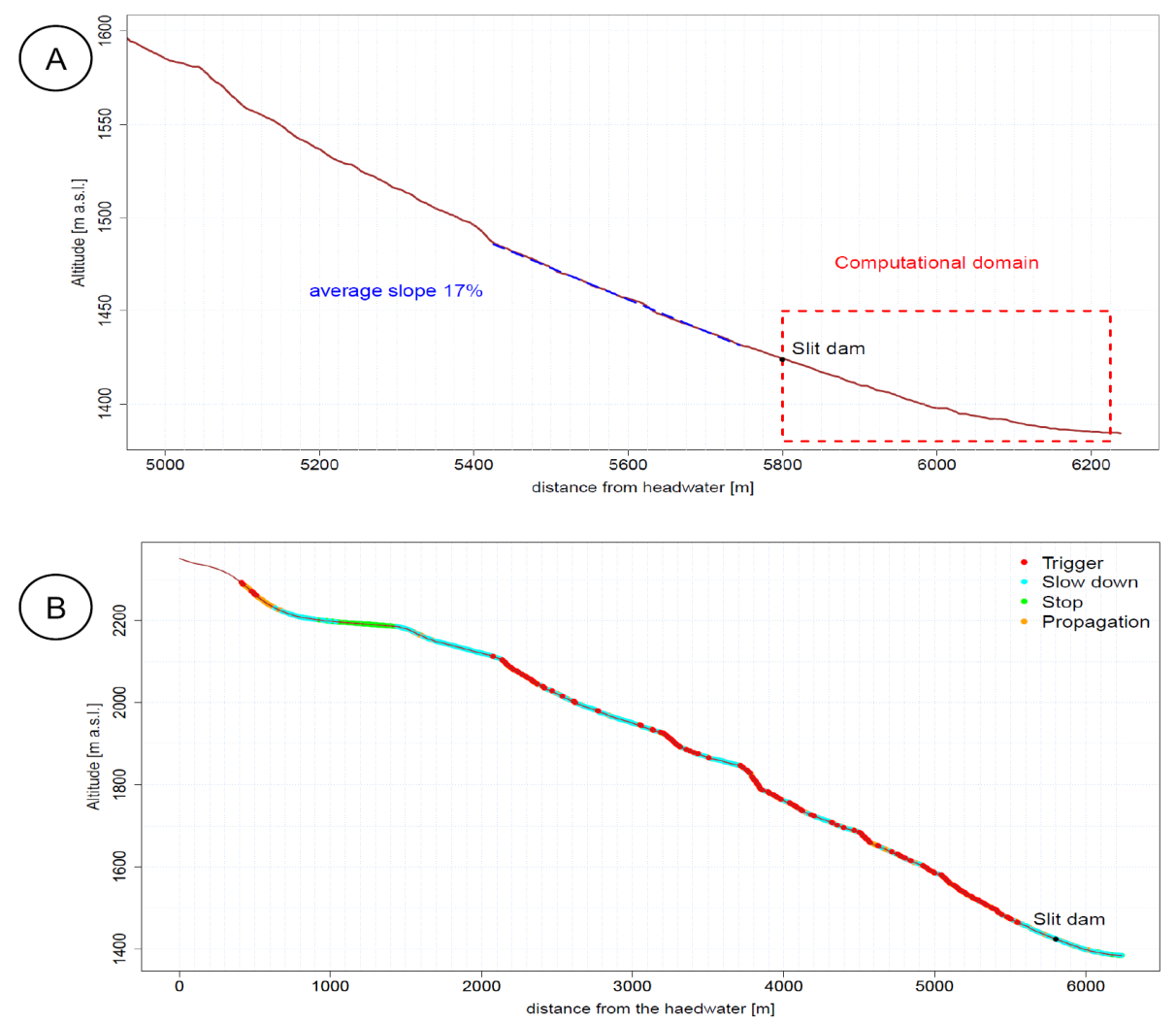

Figure 8. (a) Channel slope upstream and downstream the slit dam. The computational domain is represented with a red dashed line; (b) triggering (red) points along the channel profile according to Cavalli and Marchi (2006). Light blue points, close to the slit dam, represent decreasing velocity area.

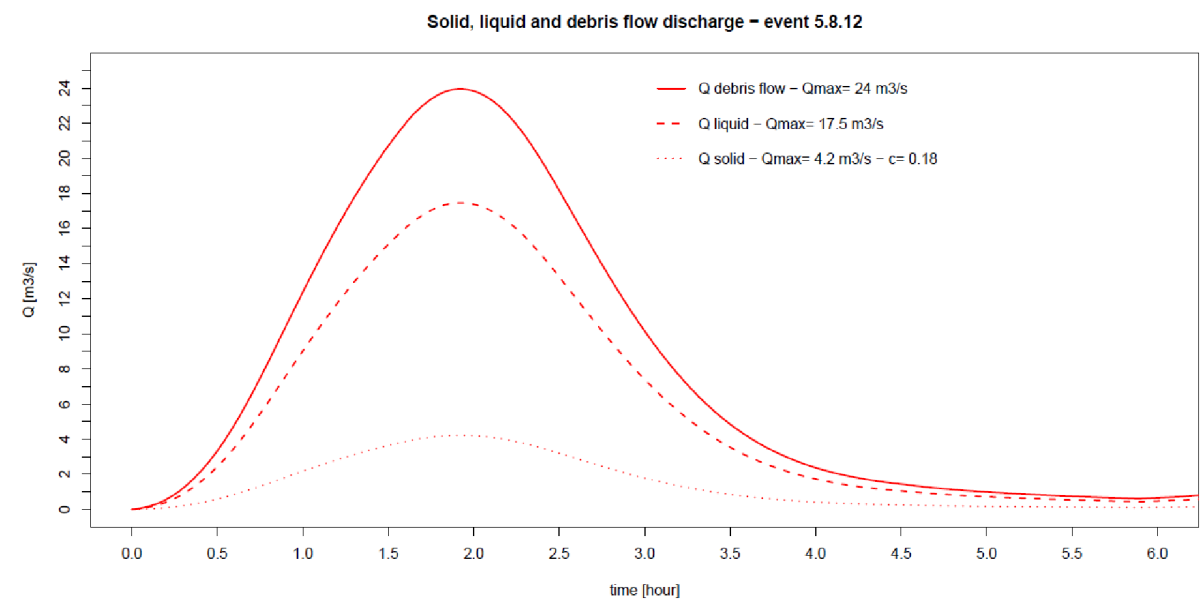

Figure 9. Boundary condition: input liquid, solid and mixture hydrograph.

in Table 1 the maximum local velocities in the immediate surroundings of the selected residential building are considerably large $\left(2 \mathrm{~m}^{3} \mathrm{~s}^{-1}\right)$. Although deposition took place as the net result of the transport process (max. $1 \mathrm{~m}$ ), relevant amounts of solid material were transported further as it is proved by the large deposition lobe downstream of the considered building.
For the subsequent fluid flow impact, the process simulation output of the primitive physical variables (i.e. debrisflow depths, velocities in $x$ and $y$ direction and thicknesses of the deposition layer) on the four vertical control sections containing the considered residential building are relevant. We considered $K=3$ representative time steps to mirror 
Table 1. Arrays of the values $\boldsymbol{W}=\left(h_{\mathrm{DF}}, v_{\mathrm{n}}, h_{\mathrm{D}}\right)^{T}$ for each control section $A_{\mathrm{p}}$, with $p=1,2,3$.

\begin{tabular}{|c|c|c|c|c|c|}
\hline $\begin{array}{l}\text { Point } \\
\text { ID }\end{array}$ & $\begin{array}{l}\text { Control } \\
\text { section }\end{array}$ & $\begin{array}{l}\text { Prog } \\
\text { coord }\end{array}$ & $\begin{array}{c}h_{\mathrm{DF}} \\
{[\mathrm{m}]}\end{array}$ & $\begin{array}{l}h_{\mathrm{D}} \\
{[\mathrm{m}]}\end{array}$ & $\begin{array}{c}v_{\mathrm{n}} \\
{\left[\mathrm{m} \mathrm{s}^{-1}\right]}\end{array}$ \\
\hline 0 & 3 & 0 & 0.14 & 0.00 & 0.424 \\
\hline 1 & 3 & 1 & 0.14 & 0.00 & 0.394 \\
\hline 2 & 3 & 2 & 0.15 & 0.00 & 0.288 \\
\hline 3 & 3 & 3 & 0.14 & 0.00 & 0.223 \\
\hline 4 & 3 & 4 & 0.12 & 0.00 & 0.313 \\
\hline 5 & 3 & 5 & 0.12 & 0.10 & 0.204 \\
\hline 6 & 3 & 6 & 0.11 & 0.17 & 0.278 \\
\hline 7 & 3 & 7 & 0.11 & 0.21 & 0.161 \\
\hline 8 & 3 & 8 & 0.11 & 0.29 & 0.246 \\
\hline 9 & 3 & 9 & 0.11 & 0.38 & 0.153 \\
\hline 10 & 3 & 10 & 0.10 & 0.44 & 0.212 \\
\hline 11 & 3 & 11 & 0.09 & 0.53 & 0.180 \\
\hline 12 & 3 & 12 & 0.09 & 0.60 & 0.102 \\
\hline 13 & 3 & 13 & 0.09 & 0.60 & 0.102 \\
\hline 14 & 3 & 14 & 0.09 & 0.65 & 0.066 \\
\hline 15 & 3 & 15 & 0.08 & 0.64 & 0.106 \\
\hline 16 & 3 & 16 & 0.09 & 0.70 & 0.014 \\
\hline 17 & 3 & 17 & 0.08 & 0.64 & 0.015 \\
\hline 18 & 3 & 18 & 0.07 & 0.57 & 0.008 \\
\hline 19 & 3 & 19 & 0.07 & 0.55 & 0.122 \\
\hline 20 & 1 & 0 & 0.00 & 0.00 & 0.000 \\
\hline 21 & 1 & 1 & 0.00 & 0.00 & 0.000 \\
\hline 22 & 1 & 2 & 0.00 & 0.00 & 0.000 \\
\hline 23 & 1 & 3 & 0.00 & 0.00 & 0.000 \\
\hline 24 & 1 & 4 & 0.00 & 0.00 & 0.000 \\
\hline 25 & 1 & 5 & 0.00 & 0.00 & 0.000 \\
\hline 26 & 1 & 6 & 0.00 & 0.00 & 0.000 \\
\hline 27 & 1 & 7 & 0.00 & 0.00 & 0.000 \\
\hline 28 & 1 & 8 & 0.00 & 0.00 & 0.000 \\
\hline 29 & 1 & 9 & 0.00 & 0.00 & 0.000 \\
\hline 30 & 1 & 10 & 0.02 & 0.00 & 0.126 \\
\hline 31 & 1 & 11 & 0.01 & 0.00 & 0.161 \\
\hline 32 & 1 & 12 & 0.02 & 0.00 & 0.160 \\
\hline 33 & 1 & 13 & 0.00 & 0.00 & 0.000 \\
\hline 34 & 1 & 14 & 0.07 & 0.00 & 0.423 \\
\hline 35 & 1 & 15 & 0.09 & 0.00 & 0.502 \\
\hline 36 & 1 & 16 & 0.09 & 0.00 & 0.411 \\
\hline 37 & 1 & 17 & 0.15 & 0.00 & 0.872 \\
\hline 38 & 1 & 18 & 0.17 & 0.00 & 1.044 \\
\hline 39 & 1 & 19 & 0.29 & 0.00 & 1.984 \\
\hline 40 & 1 & 19 & 0.29 & 0.00 & 1.984 \\
\hline 41 & 2 & 0 & 0.29 & 0.00 & 1.114 \\
\hline 42 & 2 & 1 & 0.32 & 0.00 & 0.897 \\
\hline 43 & 2 & 2 & 0.27 & 0.00 & 0.956 \\
\hline 44 & 2 & 3 & 0.24 & 0.00 & 1.181 \\
\hline 45 & 2 & 4 & 0.25 & 0.00 & 0.925 \\
\hline 46 & 2 & 5 & 0.22 & 0.00 & 0.899 \\
\hline 47 & 2 & 6 & 0.19 & 0.00 & 0.667 \\
\hline 48 & 2 & 7 & 0.16 & 0.00 & 0.618 \\
\hline 49 & 2 & 8 & 0.12 & 0.00 & 0.344 \\
\hline 50 & 2 & 9 & 0.13 & 0.00 & 0.541 \\
\hline 51 & 2 & 10 & 0.11 & 0.00 & 0.479 \\
\hline 52 & 2 & 11 & 0.08 & 0.06 & 0.220 \\
\hline
\end{tabular}

Table 1. Continued.

\begin{tabular}{lccccc}
\hline $\begin{array}{l}\text { Point } \\
\text { ID }\end{array}$ & $\begin{array}{c}\text { Control } \\
\text { section }\end{array}$ & $\begin{array}{c}\text { Prog } \\
\text { coord }\end{array}$ & $\begin{array}{c}h_{\mathrm{DF}} \\
{[\mathrm{m}]}\end{array}$ & $\begin{array}{c}h_{\mathrm{D}} \\
{[\mathrm{m}]}\end{array}$ & $\begin{array}{c}v_{\mathrm{n}} \\
{\left[\mathrm{m} \mathrm{s}^{-1}\right]}\end{array}$ \\
\hline 53 & 2 & 12 & 0.07 & 0.08 & 0.272 \\
54 & 2 & 13 & 0.05 & 0.15 & 0.157 \\
55 & 2 & 14 & 0.04 & 0.21 & 0.288 \\
56 & 2 & 15 & 0.04 & 0.21 & 0.288 \\
57 & 2 & 16 & 0.04 & 0.22 & 0.407 \\
58 & 2 & 17 & 0.03 & 0.37 & 0.340 \\
59 & 2 & 18 & 0.02 & 0.53 & 0.403 \\
60 & 2 & 19 & 0.02 & 0.59 & 0.415 \\
61 & 2 & 20 & 0.02 & 0.59 & 0.415 \\
62 & 2 & 21 & 0.01 & 0.69 & 0.391 \\
63 & 2 & 22 & 0.01 & 0.77 & 0.347 \\
64 & 2 & 23 & 0.01 & 0.75 & 0.345 \\
65 & 2 & 24 & 0.01 & 0.80 & 0.326 \\
66 & 2 & 25 & 0.01 & 0.70 & 0.358 \\
67 & 2 & 26 & 0.01 & 0.64 & 0.415 \\
68 & 2 & 27 & 0.02 & 0.63 & 0.496 \\
69 & 2 & 27 & 0.02 & 0.63 & 0.496 \\
\hline
\end{tabular}

appropriately the dynamics of the debris-flow event (compare Fig. 11).

According to Fig. 11 one may note that the building side 1 is exposed to the debris flow mainly in the initial part of the depositional event; the building side 2 is mostly exposed in the medium time range of depositional event, and the building side 3 is exposed for the entire event duration only in its upper part. This specific pattern of debris-flow propagation is due to the deflection effect exerted by an agricultural building located further upstream.

As an example we report in Table 1 for the time step $k=2 \rightarrow t_{\mathrm{k}}=7200 \mathrm{~s}$ the values of the primitive variables $\boldsymbol{W}=\left(h_{\mathrm{DF}}, v_{\mathrm{n}}, h_{\mathrm{D}}\right)^{T}$, where $v_{\mathrm{n}}$ is the flow velocity normal to the control section, $h_{\mathrm{DF}}$ is the debris-flow depth and $h_{\mathrm{D}}=z_{\mathrm{b}}$ is the thickness of the deposition layer.

Figure 12 depicts the map of maximum flow velocities (Fig. 12a) and shows as a comparison a detailed view (Fig. 12b) of the mud marks up to the second floor of the building envelope, suggesting that the dynamics of the process was characterized by high kinetic energies.

A complete process analysis should include, as outlined in Sect. 2.2, a detailed analysis of the geomechanical processes possible inducing a destabilization of the building considered. The relevance of such influences, however, can be categorically excluded in the analyzed case study, since no erosion patterns, inducing even the slightest changes in slope stability, could be detected throughout the event duration. Hence, we will assume for this case study, also concerning the subsequent impact modelling, the complete absence of significant geomechanical actions. 

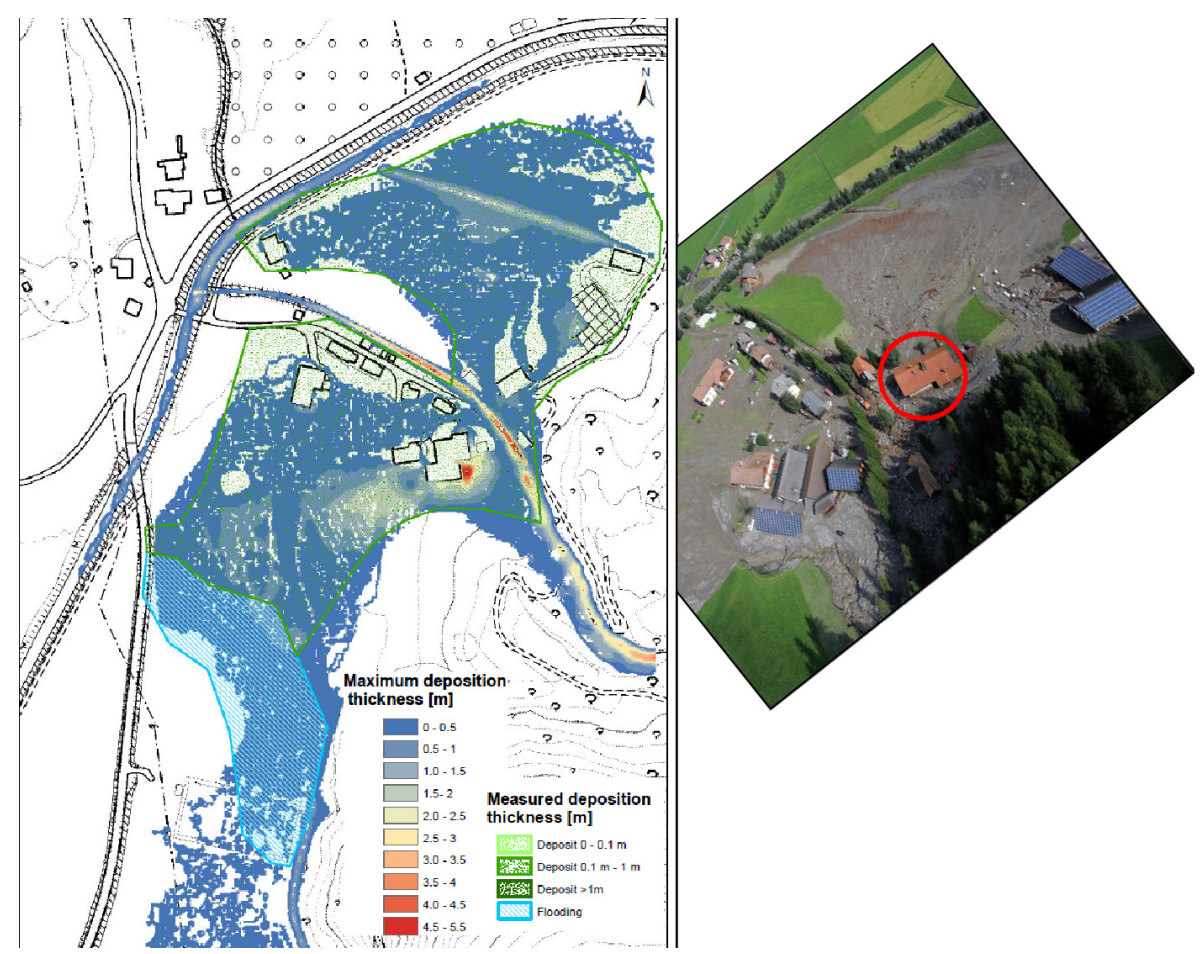

Figure 10. Left panel: comparison between simulated and measured deposition thickness. Right panel: debris-flow deposition patterns.

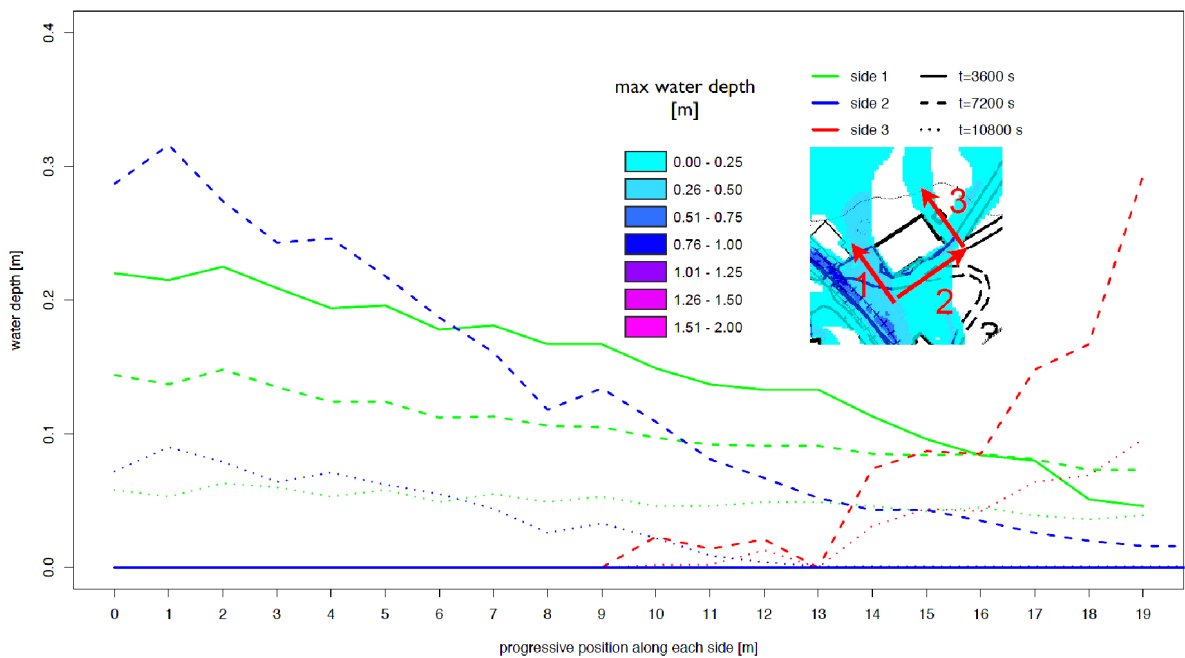

Figure 11. Water depths as a function of time as all positions along the three impacted sides of the building.

\subsection{Impact modelling}

According to Sect. 2.3.2, and specifically to the analytic expressions (Eqs. 3 and 4) the pressure distribution on the building envelope has been determined for the vertical planes normal to the envelope's walls located at each progressive coordinate (compare third column in Table 1). In Fig. 13 a specific pressure distribution for the time step $k=2 \rightarrow t_{k}=7200 \mathrm{~s}$ is shown as an example, corresponding to a specific vertical plane. Note that in this case both the velocity of the impacting debris-flow surge $\left(v_{\mathrm{n}}=0.21 \mathrm{~m} \mathrm{~s}^{-1}\right)$ and the thickness of the position layer $\left(h_{\mathrm{D}}+h_{\mathrm{S}}=0.44 \mathrm{~m}\right)$ are $>0$.

In Fig. 14 the maximum impact pressures at the building envelope perimeter are presented for the considered time step, $k=2 \rightarrow t_{k}=7200$ s. 


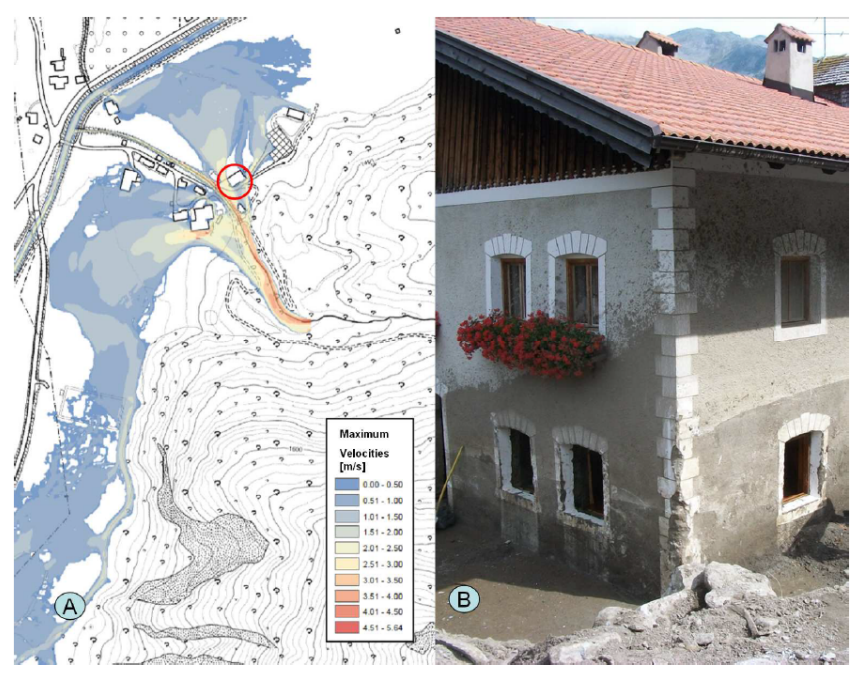

Figure 12. (a) Flow velocities and (b) mud marks reaching the second floor of the building envelope.

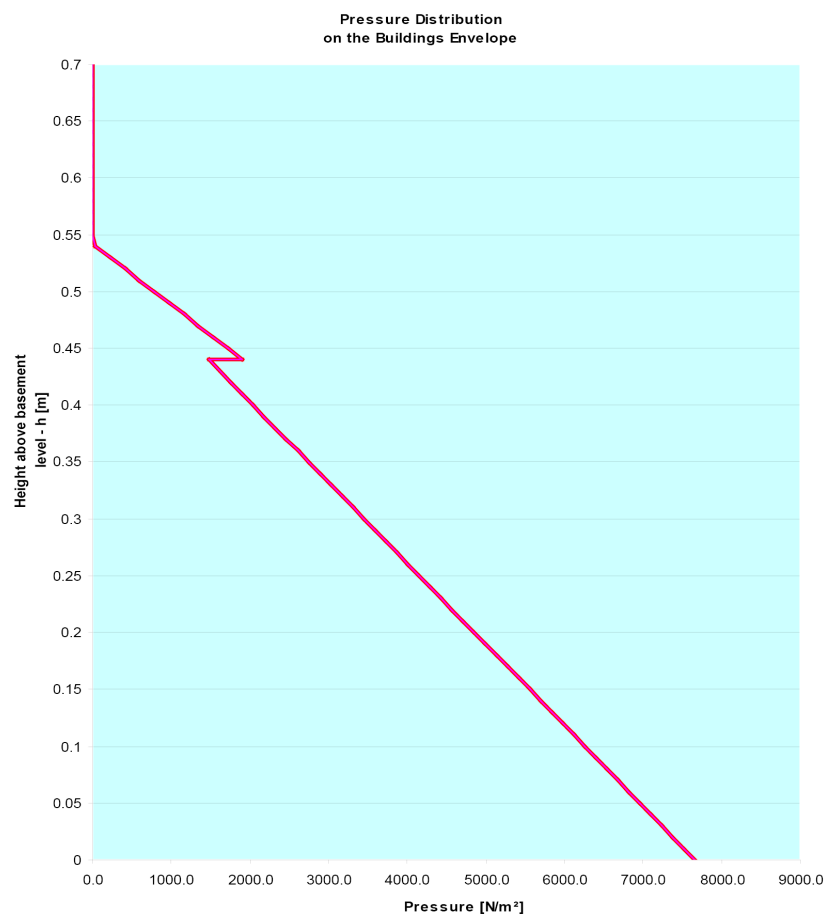

Figure 13. Pressure distribution on a selected vertical plane. The discontinuity in the pressure distribution in the upper part (layer approximately $>0.44 \mathrm{~m}$ ) results from the boundary between debrisflow material in motion and deposited volumes.

Functional to the analysis of potential intrusion of solid material in the interior volumes of the building we quantified according to Eqs. (5) and (6), regarding the three selected time steps, the exposure to wetting and the potential permeability of the building envelope (compare Table 2).

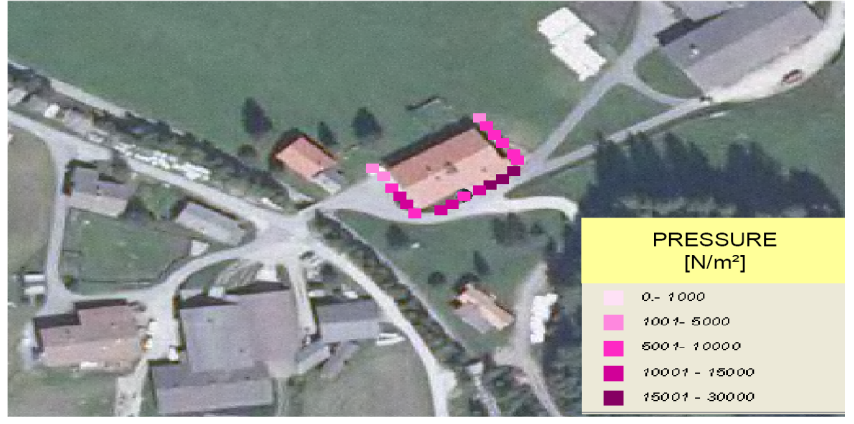

Figure 14. Representation of maximum pressure values in $\mathrm{N} \mathrm{m}^{-2}$ on the building envelope.

Table 2. Overall exposure to wetting and potential permeability for the selected time steps.

\begin{tabular}{|c|c|c|}
\hline Time step $k$ & $\begin{array}{r}\text { Overall } \\
\text { exposure } \\
\text { to wetting } \\
-\mathrm{WE}\left(t_{k}\right)- \\
\text { in } \mathrm{m}^{2} \\
\text { where }\end{array}$ & $\begin{array}{c}\text { Overall } \\
\text { potential } \\
\text { permeability } \\
-\mathrm{TO}_{\mathrm{H}}\left(t_{k}\right)- \\
\text { in } \mathrm{m}^{2} \\
\text { where }\end{array}$ \\
\hline$k=1 \rightarrow t_{k}=3600 \mathrm{~s}$ & 3.63 & 1.45 \\
\hline$k=2 \rightarrow t_{k}=7200 \mathrm{~s}$ & 10.00 & 4.36 \\
\hline$k=3 \rightarrow t_{k}=10800 \mathrm{~s}$ & 7.79 & 3.58 \\
\hline
\end{tabular}

\subsection{Structural and physical response analysis}

For the purposes of the present case study the structural analysis is restricted to the verification of one specific ultimate limit state deemed as relevant, namely STR (compare Sect. 2.4), implying failure or excessive deformation of the structure. As already stated, the reference design situation for natural hazard impact is that of an accidental situation, corresponding for each specific vertical plane to a loading spectrum similar to the example shown in Fig. 13.

With reference to the impacts of time step $k=2 \rightarrow t_{k}=7200 \mathrm{~s}$ the resulting loading configuration for the entire building is shown in Fig. 15. The distributed loading configurations are converted into their workequivalent nodal loads, since a finite element analysis using the software Sismicad 12.1 (Concrete Srl, 2012) is performed.

The relevant results of the Finite Element Analysis for each finite element of the building model (compare definition sketch in Fig. 16) are the shear forces $\left(V_{O}\right.$ and $\left.V_{Z}\right)$ shown in Fig. 17, the tensile stresses $\left(F_{O O}\right.$ and $\left.F_{Z Z}\right)$ and shear stress component $-F_{O Z}$ - represented in Fig. 18, and the bending moments $\left(M_{O O}\right.$ and $\left.M_{Z Z}\right)$ and torque $-M_{O Z}$ - visualized in Fig. 19.

For the computed stress resultants the building structure proved to be verified with respect to the ultimate limit state STR. Whereas simple exposure to wetting is not critical for 


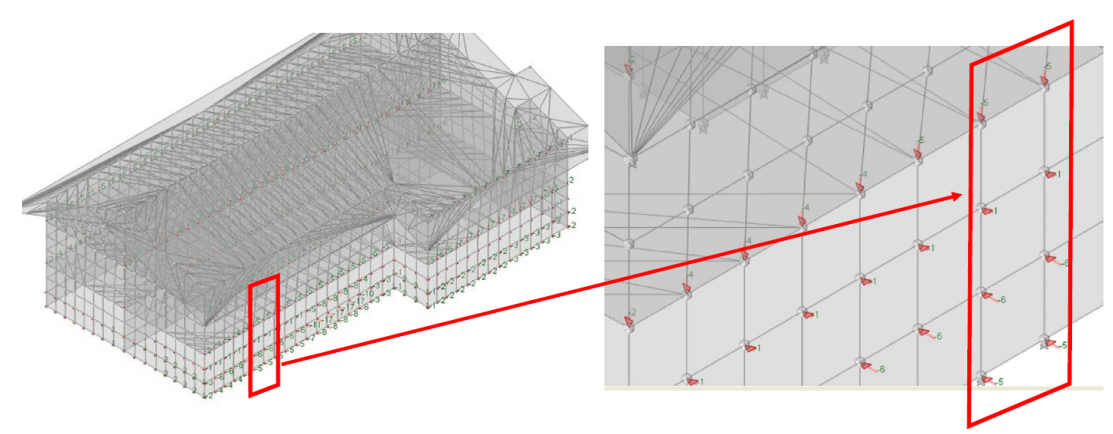

Figure 15. Work-equivalent nodal loads for the finite element structure with reference to the impacts of time step $k=2 \rightarrow t_{k}=7200 \mathrm{~s}$.
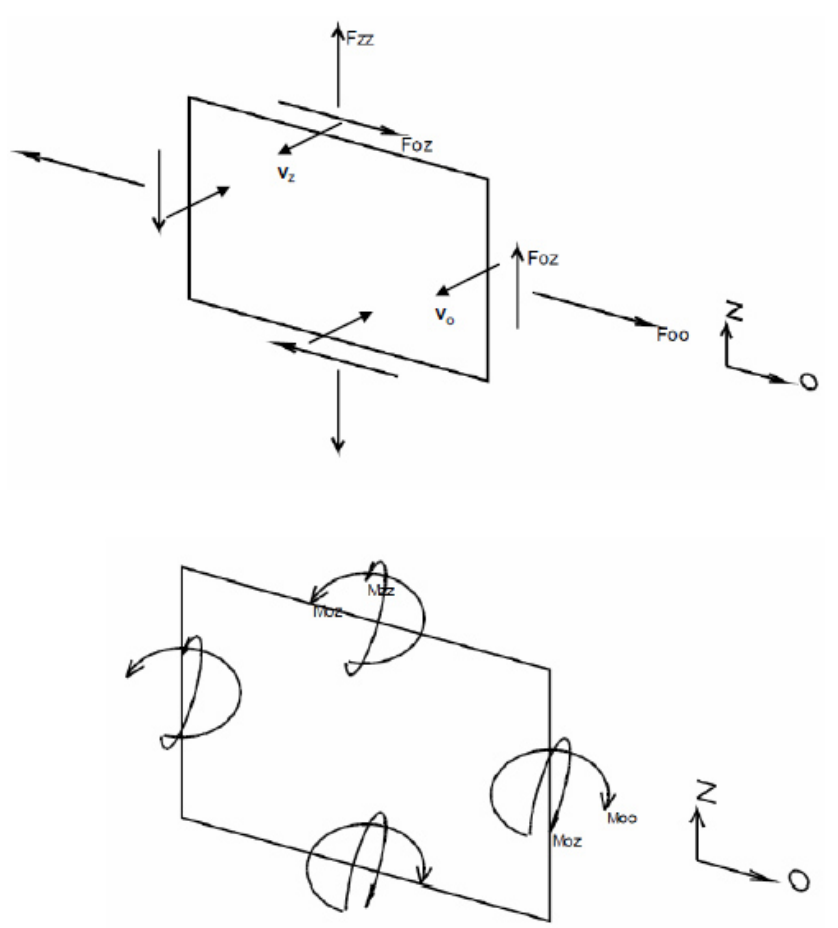

Figure 16. Definition sketch - stress resultants for each finite element.

the considered building, the no-intrusion limit state could not be verified for all openings of the building in the first floor (compare Eq. 10 and Table 2). The resulting damage susceptibility profile (i.e. structural stability, but permeability to debris-flow material intrusion) captures in its essentials the weak points which characterize the physical vulnerability of such building typologies exposed to similar ranges of debrisflow intensities.

It has to be noted that in the debris-flow case the process of moisture transport to the building walls is limited and the associated effects can be neglected.

\section{Discussion and conclusion}

The presented study extended earlier works on the deduction of empirical loss functions for buildings located on Alpine torrent fans. Taking an engineering perspective, and therefore neglecting any social implications, we presented a method to quantify vulnerability of buildings exposed to torrent processes. Starting with an overview on recent empirical studies on vulnerability, and acknowledging the overall gap in detailed studies on damage patterns, we studied analytically the loss generation mechanisms of structures exposed to hazard process impacts (i.e. process modelling and impact modelling) and the critical physical responses from a structural and building physics perspective. The proposed procedure coherently follows the Eurocode normative framework, and is of valuable information for the planning of flood-prone buildings. In addition to the existing empirical vulnerability functions, which were deduced using an ex-post approach, our conceptual and methodological setup allows to identify triggers for damage amplification (e.g. potential material intrusion through openings of the building envelope, or structural weaknesses) and may be useful in the ex-ante definition of risk mitigation strategies.

Understanding, identifying and quantifying vulnerability is an essential need for designing and implementing effective and efficient flood risk mitigation strategies in general and local protection measures in particular. The proposed damage susceptibility concept is a useful entry point for the planning process. It highlights the verifications that have to be met by the design of local protection measures.

Linking the vulnerability assessment to engineering science supports the idea that the utility of cost-benefit analysis goes far beyond the pure selection of optimal management options out of an available bundle of measures; instead, if employed in earlier phases of the risk management process such an approach may serve as an additional planning tool. Analyzing the time-varying vulnerability of elements at risk - having a crucial impact on the expected consequences of flood impacts - is increasingly becoming important for a wide spectrum of management activities within the risk governance process. Intervention planning, for example, which 

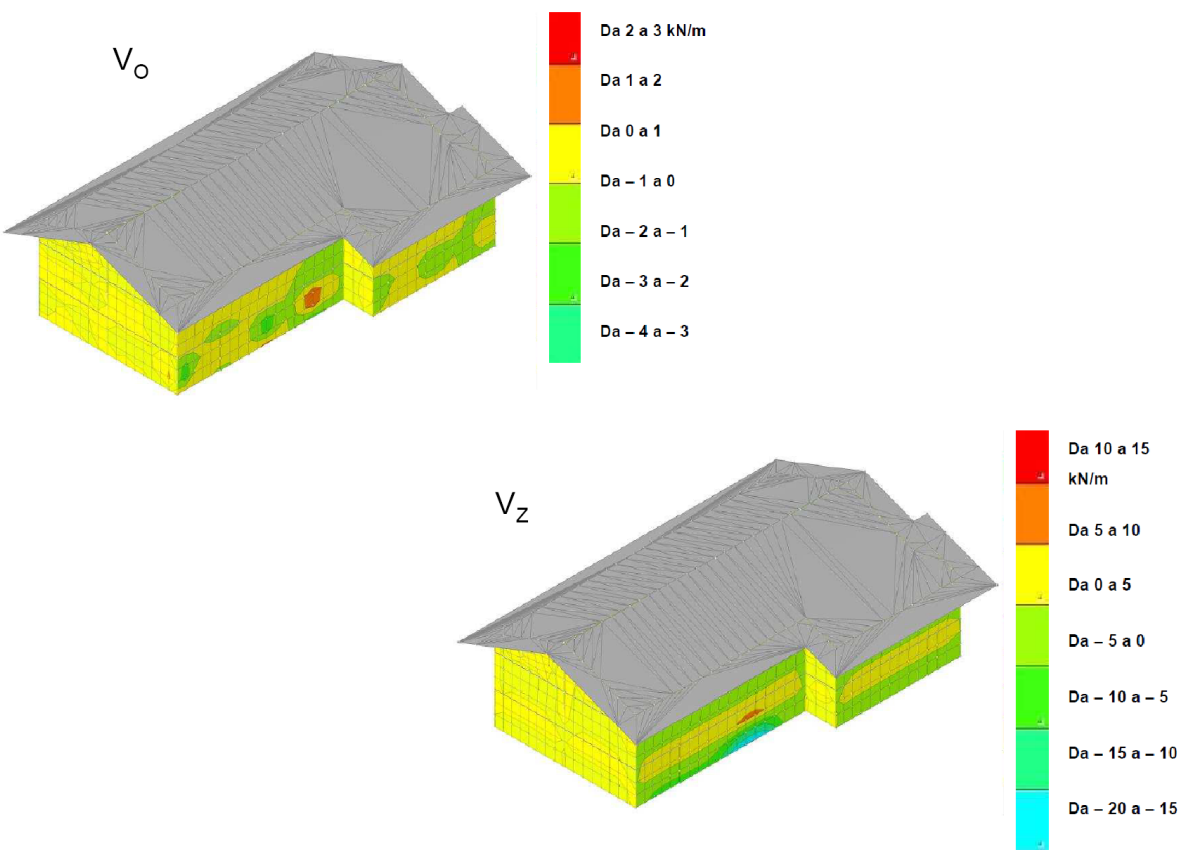

Figure 17. Shear forces $\left(V_{O}\right.$ and $\left.V_{Z}\right)$.
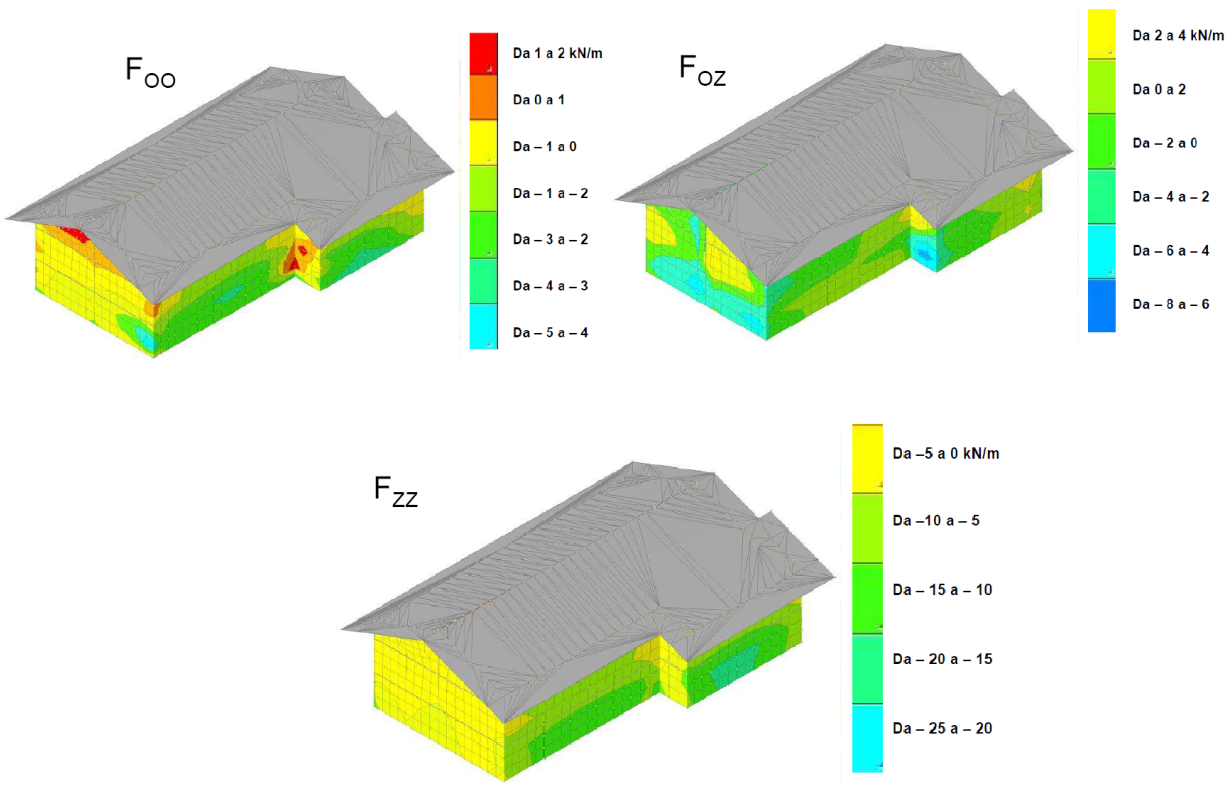

Figure 18. Tensile stresses $\left(F_{O O}\right.$ and $\left.F_{Z Z}\right)$ and shear stress component $-F_{O Z}$.

is recognized to be an effective tool to mitigate flood risk, is strongly based on the quality of the analysis of both the spatial and the temporal dynamics either of the flood hazard process or of the corresponding damaging impacts on elements at risk (Mazzorana et al., 2012b).

The method proposed, however, is very data demanding and is so far only applicable on the local scale of individual buildings located on torrent fans. Therefore, an area-wide application of this approach to an entire region still is challenging. Nevertheless, both the physical foundation and the traceability and reproducibility of the proposed vulnerability assessment method supports the identification of dynamics in natural hazard risk and contributes to an improved understanding of current risk levels.

To conclude, different concepts of vulnerability have different roots, different scientific objects, and therefore 

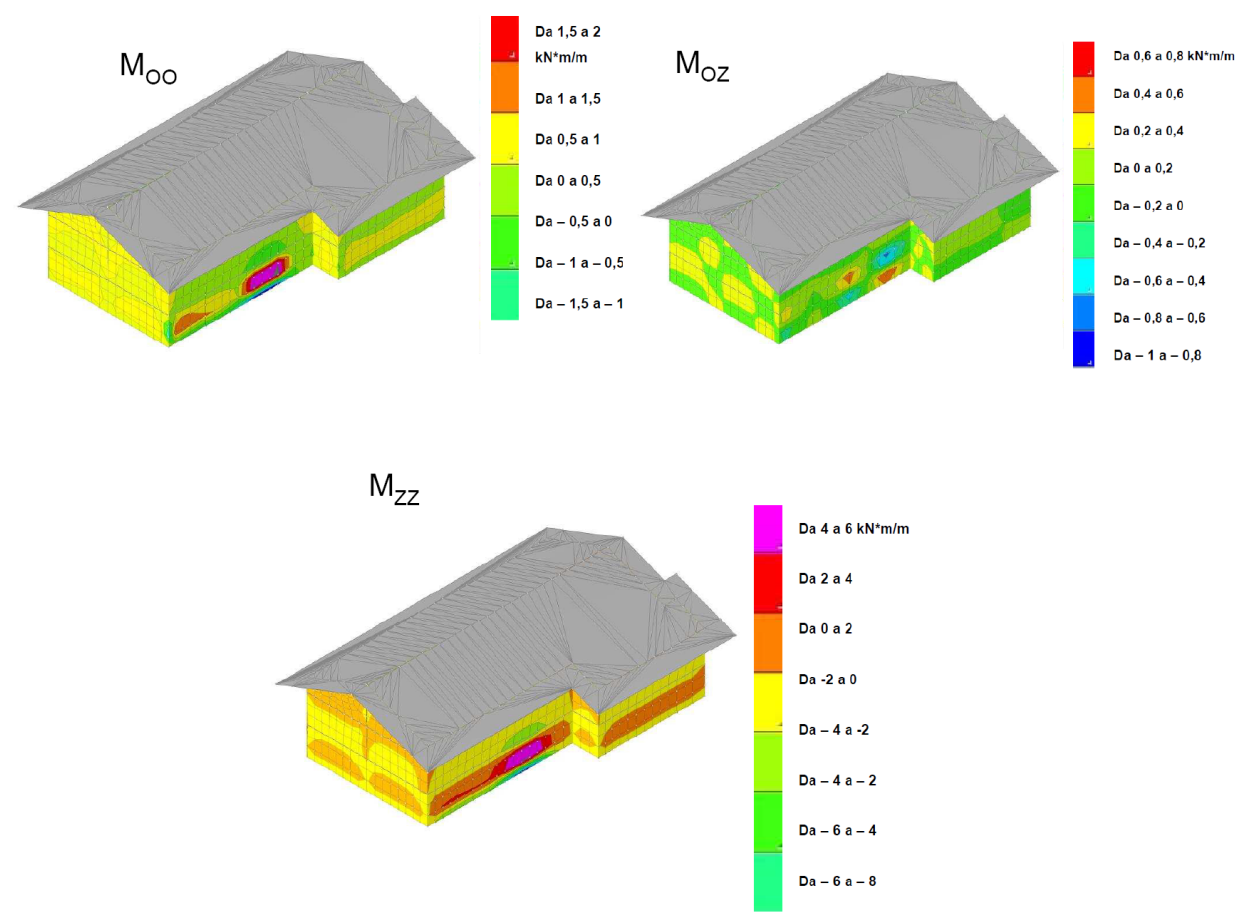

Figure 19. Bending moments $\left(M_{O O}\right.$ and $\left.M_{Z Z}\right)$ and torque $-M_{O Z}$.

different informative values. Combining contributions from empirical studies with in-depth studies on the damage patterns will allow us to better understand the triggers responsible for vulnerability, and will lead to a deeper understanding of mountain hazard risk. This is a first step to increase the resilience of mountain communities.

Acknowledgements. The authors wish to kindly acknowledge P. Ronco, O. Mavrouli and one anonymous referee for their constructive suggestions improving earlier versions of this manuscript. Moreover the authors would like to express their sincere thanks to the editor, M. Mikoš.

Edited by: M. Mikos

\section{References}

Armanini, A., Fraccarollo, L., and Rosatti, G.: Two-dimensional simulation of debris flows in erodible channels, Comput. Geosci., 35, 993-1006, 2009.

Armanini, A., Larcher, M., and Odorizzi, M.: Dynamic impact of a debris flow against a vertical wall, Ital. J. Eng. Geol. Environ., 11, 1041-1049, 2011.

Birkmann, J., Cardona, O. M., Carreño, M. L., Barbat, A. H., Pelling, M., Schneiderbauer, S., Kienberger, S., Keiler, M., Alexander, D., Zeil, P., and Welle, T.: Framing vulnerability, risk and societal responses: the MOVE framework, Nat. Hazards, 67, 193-211, 2013.
Cavalli, M., and Marchi, L.: Identificazione preliminare delle aree di pericolo legate a fenomeni torrentizi, Consiglio Nazionale delle Ricerche - CNR, Istituto di Ricerca per la Protezione Idrogeologica Padova - IRPI, Padova, 2006.

Comiti, F., Mao, L., Preciso, E., Picco, L., Marchi, L., and Borga, M.: Large wood and flash floods: evidences from the 2007 event in the Davča basin (Slovenia), in: Monitoring, simulation, prevention and remediation of dense and debris flow II, edited by: De Wrachien, D., Brebbia, C. A., and Lenzi, M. A., WIT Transactions on Information and Communication Technologies 39, WIT Press, Southampton, 173-182, 2008.

Concrete srl: Sismicad 12.1 manuale d'uso, http://www.concrete.it/ sismicad12/, last access: 12 March 2013, 2012.

Cutter, S. and Finch, C.: Temporal and spatial changes in social vulnerability to natural hazards, P. Natl. Acad. Sci. USA, 105, 2301-2306, 2008.

de Vries, D.: Being temporal and vulnerability to natural disasters, in: Perspectives on social vulnerability, edited by: Warner, K., United Nations University, Institute for Environment and Human Security, Bonn, 36-49, 2007.

Diehl, T.: Potential drift accumulation at bridges, Washington Publication No. FHWA-RD-97-028, US Department of Transportation, Federal Highway Administration Research and Development, Turner-Fairbank Highway Research Center, Springfield, Virginia, 1997.

Feix, J. and Walkner, R.: Betonbau: Grundlagen der Bemessung nach EC2, Studia Universitätsverlag, Innsbruck, 2012.

Fell, R., Corominas, J., Bonnard, C., Cascini, L., Leroi, E., and Savage, W.: Guidelines for landslide susceptibility, hazard and risk zoning for land-use planning, Eng. Geol., 102, 85-98, 2008. 
Fuchs, S.: Susceptibility versus resilience to mountain hazards in Austria - paradigms of vulnerability revisited, Nat. Hazards Earth Syst. Sci., 9, 337-352, doi:10.5194/nhess-9-337-2009, 2009.

Fuchs, S.: Cost-benefit analysis of natural hazard mitigation, in: Encyclopedia of natural hazards, edited by: Bobrowski, P., Springer, Dordrecht, 121-125, 2013.

Fuchs, S., Heiss, K., and Hübl, J.: Towards an empirical vulnerability function for use in debris flow risk assessment, Nat. Hazards Earth Syst. Sci., 7, 495-506, doi:10.5194/nhess-7-4952007, 2007.

Fuchs, S., Birkmann, J., and Glade, T.: Vulnerability assessment in natural hazard and risk analysis: current approaches and future challenges, Nat. Hazards, 64, 1969-1975, 2012a.

Fuchs, S., Ornetsmüller, C., and Totschnig, R.: Spatial scan statistics in vulnerability assessment - an application to mountain hazards, Nat. Hazards, 64, 2129-2151, 2012b.

Fuchs, S., Keiler, M., Sokratov, S. A., and Shnyparkov, A.: Spatiotemporal dynamics: the need for an innovative approach in mountain hazard risk management, Nat. Hazards, 68, 12171241, 2013.

Gall, M., Borden, K., and Cutter, S.: When do losses count? Six fallacies of natural hazards loss data, B. Am. Meteorol. Soc., 90, 799-809, 2009

Gallerani, V., Viaggi, D., and Zanni, G.: Manuale di estimo, McGraw-Hill, Milano, 2011.

Gulvanessian, H.: EN 1990 Eurocode "Basis of structural design" - the innovative head Eurocode, Steel Construct., 2, 222-227, 2009.

Gulvanessian, H., Calgaro, J.-A., Holický, M.: Designers' guide to EN 1990, Eurocode: Basis of structural design, Thomas Telford Ltd, London, 2004.

Hawkesbury-Nepean Floodplain Management Steering Committee (Ed.): Reducing vulnerability of buildings to flood damage, Hawkesbury-Nepean Floodplain Management Steering Committee, Parramatta, 2006.

Holub, M. and Fuchs, S.: Benefits of local structural protection to mitigate torrent-related hazards, in: Risk Analysis VI, edited by: Brebbia, C. and Beriatos, E., WIT Transactions on Information and Communication Technologies 39, WIT, Southampton, 401411,2008

Holub, M. and Fuchs, S.: Mitigating mountain hazards in Austria - legislation, risk transfer, and awareness building, Nat. Hazards Earth Syst. Sci., 9, 523-537, doi:10.5194/nhess-9-5232009, 2009.

Holub, M., Suda, J., and Fuchs, S.: Mountain hazards: reducing vulnerability by adapted building design, Environ. Earth Sci., 66, 1853-1870, 2012.

Hübl, J., Bunza, G., Hafner, K., and Klaus, W.: ETAlp - Erosion, Transport in Alpinen Systemen "Stummer Zeugen Katalog”, Projektteam ETAlp, Wien, 2003.

Hufschmidt, G.: A comparative analysis of several vulnerability concepts, Nat. Hazards, 58, 621-643, 2011.

Ishikawa, Y.: Studies on disasters caused by debris flows carrying logs down mountains, SABO Division, Public Works Research Institute, Ministry of Construction, Tokyo, 45-75, 1990.

Iverson, R.: The physics of debris flows, Rev. Geophys., 35, 245296, 1997.
Jakob, M.: Events on cones and fans: recurrence interval and magnitude, in: Dating torrential processes on fans and cones, edited by: Schneuwly-Bollschweiler, M., Stoffel, M., and Rudolf-Miklau, F., Springer, Dordrecht, 95-108, 2013.

Jakob, M., Stein, D., and Ulmi, M.: Vulnerability of buildings to debris flow impact, Nat. Hazards, 60, 241-261, 2012.

Kappes, M., Keiler, M., von Elverfeldt, K., and Glade, T.: Challenges of analyzing multi-hazard risk: a review, Nat. Hazards, 64, 1925-1958, 2012a.

Kappes, M., Papathoma-Köhle, M., and Keiler, M.: Assessing physical vulnerability for multi-hazards using an indicator-based methodology, Appl. Geogr., 32, 577-590, 2012 b.

Kienholz, H., Krummenacher, B., Kipfer, A., and Perret, S.: Aspects of integral risk management in practice - considerations with respect to mountain hazards in Switzerland, Öster. Wasser Abfallw., 56, 43-50, 2004.

Mao, L. and Comiti, F.: The effects of large wood elements during an extreme flood in a small tropical basin of Costa Rica, in: Debris flow III, edited by: De Wrachien, D. and Brebbia, C. A., WIT Transactions on Information and Communication Technologies 39, WIT Press, Southampton, 225-236, 2010.

Mazzorana, B. and Fuchs, S.: Fuzzy Formative Scenario Analysis for woody material transport related risks in mountain torrents, Environ. Modell. Softw., 25, 1208-1224, 2010.

Mazzorana, B., Comiti, F., Volcan, C., and Scherer, C.: Determining flood hazard patterns through a combined stochasticdeterministic approach, Nat. Hazards, 59, 301-316, 2011.

Mazzorana, B., Comiti, F., Scherer, C., and Fuchs, S.: Developing consistent scenarios to assess flood hazards in mountain streams, J. Environ. Manage., 94, 112-124, 2012a.

Mazzorana, B., Levaggi, L., Formaggioni, O., and Volcan, C.: Physical vulnerability assessment based on fluid and classical mechanics to support cost-benefit analysis of flood risk mitigation strategies, Water, 4, 196-218, 2012b.

Mazzorana, B., Levaggi, L., Keiler, M., and Fuchs, S.: Towards dynamics in flood risk assessment, Nat. Hazards Earth Syst. Sci., 12, 3571-3587, doi:10.5194/nhess-12-3571-2012, 2012c.

Mazzorana, B., Comiti, F., and Fuchs, S.: A structured approach to enhance flood hazard assessment in mountain streams, Nat Hazards, 67, 991-1009, 2013.

Papathoma-Köhle, M., Kappes, M., Keiler, M., and Glade, T.: Physical vulnerability assessment for alpine hazards: state of the art and future needs, Nat. Hazards, 58, 645-680, 2011.

Papathoma-Köhle, M., Keiler, M., Totschnig, R., and Glade, T.: Improvement of vulnerability curves using data from extreme events: debris flow event in South Tyrol, Nat. Hazards, 64, 2083 2105, 2012.

Pierson, T. C. and Costa, J. E.: A rheologic classification of subaerial sediment-water flows, Geol. Soc. Am. Rev. Eng. Geol., 7, 1-12, 1987.

Pitman, E. and Le, L.: A two-fluid model for avalanche and debris flows, Philos. T. Roy. Soc. A, 363, 1573-1601, 2005.

Plaxis: Scientific manual, http://www.plaxis.nl/files/files/ 2D2011-4-Scientific.pdf, last access: 12 February 2013, 2011.

Quan Luna, B., Blahut, J., van Westen, C. J., Sterlacchini, S., van Asch, T. W. J., and Akbas, S. O.: The application of numerical debris flow modelling for the generation of physical 
vulnerability curves, Nat. Hazards Earth Syst. Sci., 11, 20472060, doi:10.5194/nhess-11-2047-2011, 2011.

Rigon, R., D'Odorico, P., and Bertoldi, G.: The geomorphic structure of the runoff peak, Hydrol. Earth Syst. Sci., 15, 1853-1863, doi:10.5194/hess-15-1853-2011, 2011.

Rosatti, G. and Begnudelli, L.: Two-dimensional simulation of debris flows over mobile bed: Enhancing the TRENT2D model by using a well-balanced Generalized Roe-type solver, Comput. Fluids, 71, 179-195, 2013.

Rosatti, G. and Fraccarollo, L.: A well-balanced approach for flows over mobile-bed with high sediment transport, J. Comput. Phys., 220, 312-338, 2006.

Slaymaker, O.: The distinctive attributes of debris torrents, Hydrolog. Sci. J., 33, 567-573, 1988.

Steinke, P.: Finite-Elemente-Methode, Springer, Heidelberg, 2012.

Totschnig, R. and Fuchs, S.: Mountain torrents: quantifying vulnerability and assessing uncertainties, Eng. Geol., 155, 31-44, 2013.
Totschnig, R., Sedlacek, W., and Fuchs, S.: A quantitative vulnerability function for fluvial sediment transport, Nat. Hazards, 58, 681-703, 2011.

Wakker, P. P.: Prospect theory for risk and ambiguity, Cambridge University Press, Cambridge, 2010.

Walhorn, E., Kölke, A., Hübner, B., and Dinkler, D.: Fluid-structure coupling within a monolithic model involving free surface flows, Comput. Struct., 83, 2100-2111, 2005.

Wisner, B.: Assessment of capability and vulnerability, in: Mapping vulnerability. Disasters, development and people, edited by: Bankoff, G., Frerks, G., and Hilhorst, D., Earthscan, London, 183-193, 2004.

Zienkiewicz, O. C., Taylor, R. L., and Zhu, J. Z.: The Finite Element method: Its basis and fundamentals, Butterworth-Heinemann, Oxford, 2005. 